\title{
Digital Commons@Montana Tech
}

Summer 2016

\section{Comparison of Two Surface Contamination Sampling Techniques Conducted for the Characterization of Two Pajarito Site Manhattan Project National Historic Park Properties}

Lopez Tammy

Montana Tech of the University of Montana

Follow this and additional works at: http://digitalcommons.mtech.edu/grad_rsch

Part of the Occupational Health and Industrial Hygiene Commons

\section{Recommended Citation}

Tammy, Lopez, "Comparison of Two Surface Contamination Sampling Techniques Conducted for the Characterization of Two Pajarito Site Manhattan Project National Historic Park Properties" (2016). Graduate Theses \& Non-Theses. 91.

http://digitalcommons.mtech.edu/grad_rsch/91 


\section{LA-UR-16-25771}

Approved for public release; distribution is unlimited.

Title: $\quad$ Comparison of Two Surface Contamination Sampling Techniques Conducted for the Characterization of Two Pajarito Site Manhattan Project National Historic Park Properties

Author(s): Lopez, Tammy Ann

Intended for: Report

Issued: 
Disclaimer:

Los Alamos National Laboratory, an affirmative action/equal opportunity employer, is operated by the Los Alamos National Security, LLC for the National Nuclear Security Administration of the U.S. Department of Energy under contract DE-AC52-06NA25396. By approving this article, the publisher recognizes that the U.S. Government retains nonexclusive, royalty-free license to publish or reproduce the published form of this contribution, or to allow others to do so, for U.S. Government purposes. Los Alamos National Laboratory requests that the publisher identify this article as work performed under the auspices of the U.S. Department of Energy. Los Alamos National Laboratory strongly supports academic freedom and a researcher's right to publish; as an institution, however, the Laboratory does not endorse the viewpoint of a publication or guarantee its technical correctness. 
Comparison of Two Surface Contamination Sampling Techniques Conducted for the Characterization of Two Pajarito Site Manhattan Project National Historic Park Properties

by:

Tammy A. Lopez

A report submitted in partial fulfillment of the requirements for the degree of

Master of Science

Industrial Hygiene Distance Learning / Professional Track

Montana Tech of the University of Montana 2016 


\section{Abstract}

Technical Area-18 (TA-18), also known as Pajarito Site, is located on Los Alamos National Laboratory property and has historic buildings that will be included in the Manhattan Project National Historic Park. Characterization studies of metal contamination were needed in two of the four buildings that are on the historic registry in this area, a "battleship" bunker building (TA-18-0002) and the Pond cabin (TA-18-0029). However, these two buildings have been exposed to the elements, are decades old, and have porous and rough surfaces (wood and concrete). Due to these conditions, it was questioned whether standard wipe sampling would be adequate to detect surface dust metal contamination in these buildings. Thus, micro-vacuum and surface wet wipe sampling techniques were performed side-by-side at both buildings and results were compared statistically. A two-tail paired t-test revealed that the micro-vacuum and wet wipe techniques were statistically different for both buildings. Further mathematical analysis revealed that the wet wipe technique picked up more metals from the surface than the microvacuum technique. Wet wipes revealed concentrations of beryllium and lead above internal housekeeping limits; however, using an yttrium normalization method with linear regression analysis between beryllium and yttrium revealed a correlation indicating that the beryllium levels were likely due to background and not operational contamination. PPE and administrative controls were implemented for National Park Service (NPS) and Department of Energy (DOE) tours as a result of this study. Overall, this study indicates that the micro-vacuum technique may not be an efficient technique to sample for metal dust contamination.

Keywords: beryllium, lead, cadmium, Pajarito Site, TA-18, micro-vacuum sampling, wet wipe sampling 


\section{Dedication}

First and foremost, I wish to thank God for all the blessings and opportunities He has given me in my life. Thank you to my co-workers and supervisors, past and present, who assisted and supported me in the pursuit of my degree. I'd also like to thank my husband, and all my family, for being patient with me and supporting me always. I dedicate this to my son, Gilbert. May you always know you are the light of my life, the twinkle in my eye, the beat in my heart, and the answer to my prayers. 


\section{Acknowledgements}

This study was done for the National Park Service (NPS) under the U.S. Department of Energy (DOE) at Los Alamos National Laboratory. Funding was provided by the Utilities and Infrastructure Facility Operations (FOD) Division as well as the Associate Directorate for Environmental Safety and Health (ADESH). 


\section{Table of Contents}

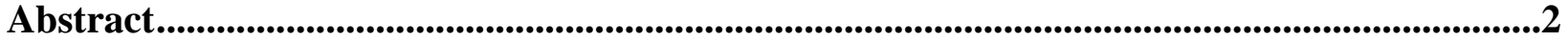

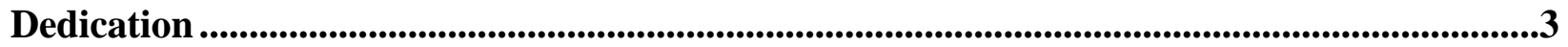

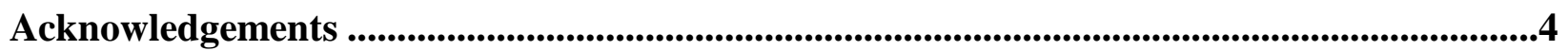

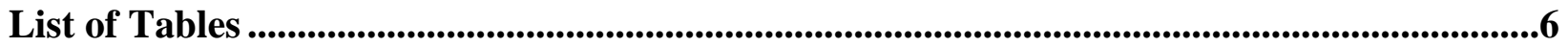

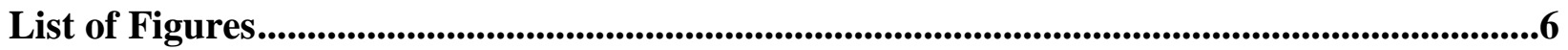

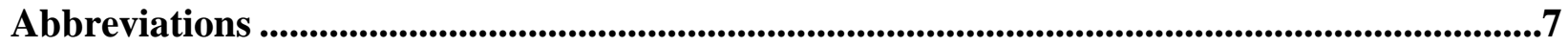

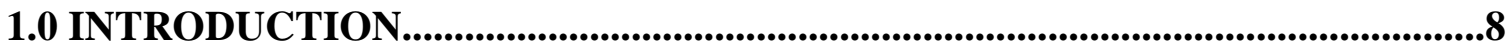

2.0 PROJECT OBJECTIVES.................................................................................................13

3.0 BACKGROUND OF BERYLLIUM, CADMIUM, AND LEAD...............................13

3.1 HISTORY ..................................................................................................... 13

3.2 TOXICOLOGY AND RELATED DISEASES ............................................... 14

3.3 REGULATIONS ............................................................................................... 15

4.0 MATERIALS AND METHODS ................................................................................16

4.1 Sampling Design and Rationale .......................................................................... 16

4.2 Field Methods and Procedures ......................................................................... 19

5.0 Results and Discussion..................................................................................................27

5.1 Comparison Statistics of Micro-vacuum vs. Wet Wipe Sampling ............ 27

5.2 Determination of Background Beryllium Levels Due to the Soil vs.

Operational Contamination ......................................................................................... 32

5.3 Presence of $\mathrm{Pb}$ and $\mathrm{Cd}$.................................................................................... 33

6.0 Conclusions...................................................................................................................34

7.0 References ...........................................................................................................................36

8.0 Appendix A: Raw Data....................................................................................................38 


\section{List of Tables}

Table I: Bunker Building Micro-vacuum vs. Wipe Comparison

Table II: Bunker Building Micro-vacuum vs. Wipe Comparison

Table III: Pond Cabin Micro-vacuum vs. Wipe Comparison

Table IV: Pond Cabin Micro-vacuum vs. Wipe Comparison

\section{List of Figures}

Figure 1: Pajarito Club established by Ashley Pond

Figure 2: TA-18 location within LANL boundaries and in relation to Los Alamos town site

Figure 3: TA-18-0002 Battleship Bunker

Figure 4: TA-18-0029 Pond Cabin

Figure 5: Sketch of the bunker building sampled areas

Figure 6: Sketch of the Pond cabin sampled areas.

Figure 7: Pictures of the Bunker building sample locations

Figure 8A: Pictures of the main room of the Pond cabin sampled areas.

Figure 8B: Pictures of the bedroom and pantry of the Pond cabin

Figure 9: Yttrium vs. Beryllium Linear Regression Plot 


\section{Abbreviations}

$\begin{array}{ll}\text { U.S. } & \text { United States } \\ \text { NPS } & \text { National Park Service } \\ \text { LANL } & \text { Los Alamos National Laboratory } \\ \text { NM } & \text { New Mexico } \\ \text { TA-18 } & \text { Technical Area-18 } \\ \text { DOE } & \text { Department of Energy } \\ \text { ADESH } & \text { Associate Directorate of Environmental Safety and Health } \\ \text { ASTM } & \text { American Society for Testing and Materials } \\ \text { NIOSH } & \text { National Institute of Occupational Safety and Health } \\ \text { PPE } & \text { Personal Protective Equipment } \\ \text { ID } & \text { Identification } \\ \text { PVC } & \text { Polyvinyl chloride } \\ \text { MCE } & \text { Mixed Cellulose Ester } \\ \text { NELAC } & \text { National Environmental Laboratory Accreditation Conference } \\ \text { AIHA-LAP } & \text { American Industrial Hygiene Association - Laboratory Accreditation Programs } \\ \text { Be } & \text { Beryllium } \\ \text { Pb } & \text { Lead } \\ \text { HUD } & \text { U.S. Department of Housing and Urban Development } \\ \text { LOD } & \text { Limit of Detection } \\ \text { RL } & \text { Reporting Limit } \\ \text { ALS } & \text { Australian Laboratory Services } \\ \text { Al } & \text { Aluminum } \\ \text { Fe } & \text { Iron } \\ \text { Y } & \text { Yttrium }\end{array}$




\subsection{INTRODUCTION}

The United States (U.S.) National Park Service (NPS) is currently moving forward with development of a National Historic Park dedicated to the Manhattan Project, a research and development project implemented on U.S. soil, which resulted in the world's first atomic bomb that ended World War II. The Manhattan Project National Historic Park will include three areas involved in the "dawn of the atomic age”: the Oak Ridge Reservation in Oak Ridge, Tennessee; Hanford Engineer Works in Hanford, Washington; and Los Alamos National Laboratory (LANL) in Los Alamos, New Mexico (NM) (“Manhattan Project,” n.d.). Thus far, sites at Oak Ridge and Hanford are already open to the public ("Manhattan Project”, n.d.). NPS has requested that LANL begin characterization of the LANL buildings that will be part of the park so that eventually public access can be granted. Technical Area 18 (TA-18) is one of three areas at LANL that is to be included in the park and is located at the intersection of two canyons, Pajarito Canyon and Three Mile Canyon (“Manhattan Project,” n.d.; McGehee et al., 2009). Several buildings at TA-18, also known as Pajarito Site, are listed on the National Register of Historic Landmarks and will be included in the park because of their historical contribution to nuclear weapons and critical assembly research and development conducted during the World War II and Cold War eras (McGehee et al., 2009).

Pajarito Site was originally a dude ranch established in 1914 by a gentleman named Ashley Pond for a Pajarito Club he planned to start with other individuals; a few log cabins were built on the property, including the historic TA-18-0029 Pond Cabin (see Figure 1) (McGehee et al., 2009). The ranch was abandoned in 1916 (McGehee et al., 2009). Ashley Pond then founded a boy’s private ranch school in the Los Alamos area in 1917; the site was later chosen for the Manhattan Project location by Dr. Robert Oppenheimer (McGehee et al., 2009). 


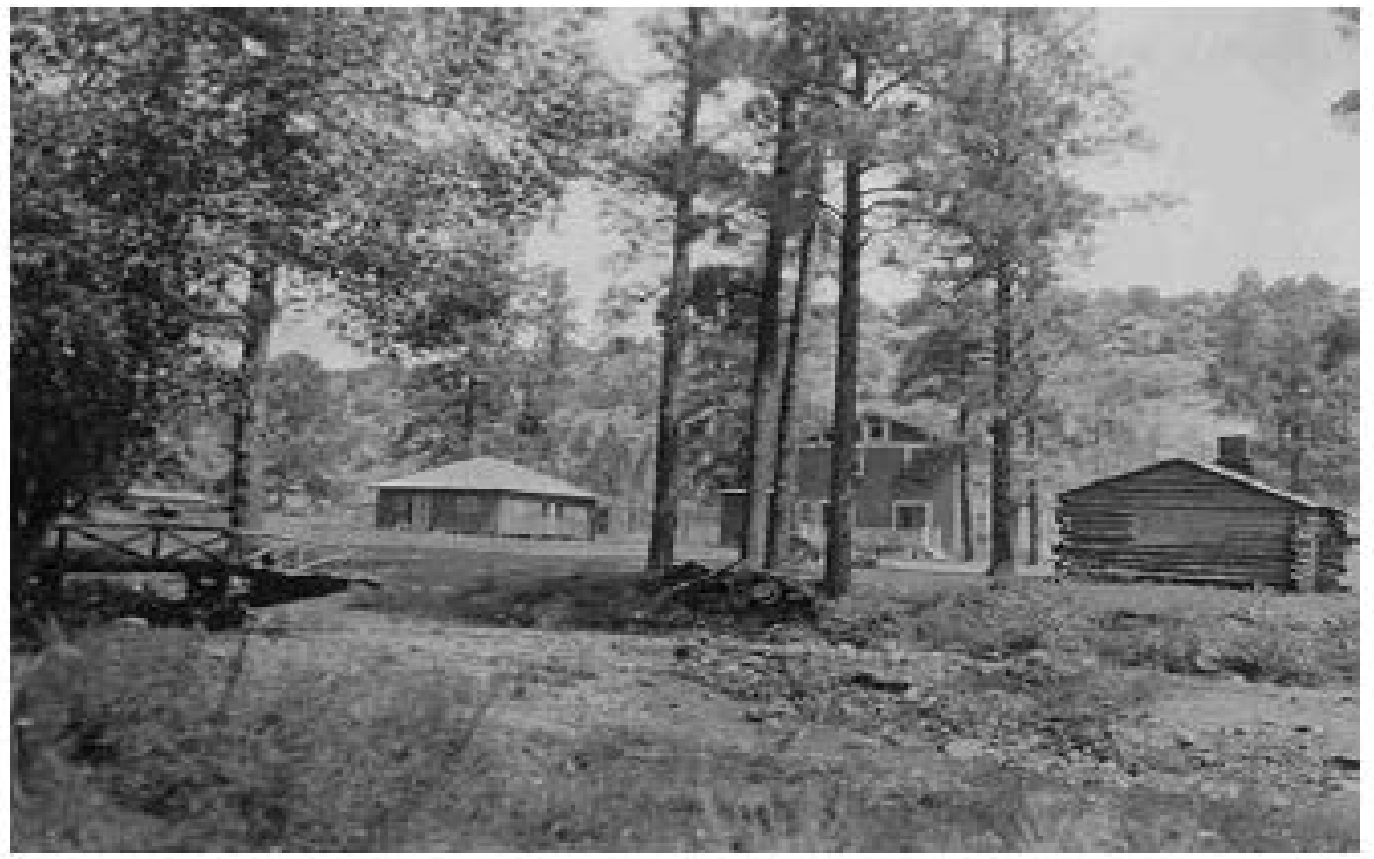

Figure 1: Pajarito Club established by Ashley Pond; photo courtesy of Los Alamos Historical Society (McGehee et al., 2009).

Once the Manhattan Project began in 1943, scientists needed an area segregated geographically from the rest of the Manhattan Project technical area, which was located in the present day town site of Los Alamos, to study the rates of spontaneous fission reactions with radioactive material samples (McGehee et al., 2009). The geographical segregation was critical due to extreme instrument sensitivity (McGehee et al., 2009). The Pajarito Site was perfect for this work since it was secluded away from, but close enough to, the rest of the Manhattan Project technical areas and already had a few log buildings that could be utilized (McGehee et al., 2009). Figure 2 shows the TA-18 location within the LANL boundaries and in relation to the Los Alamos town site (McGehee et al., 2009). 


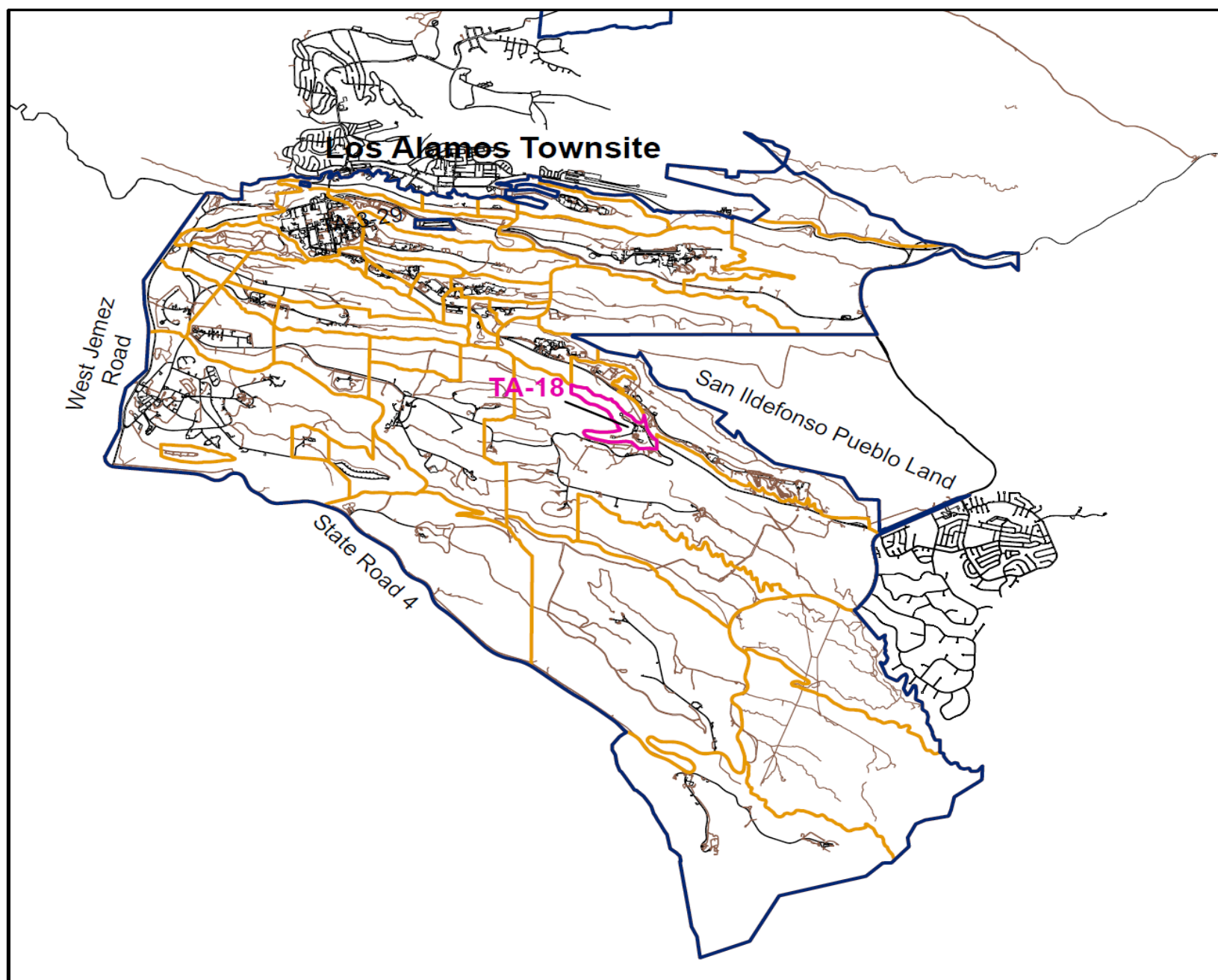

\section{Los Alamos National Laboratory Cultural Resources Team ENV-EAQ Ecology \& Air Quality Group}

\section{LANL Boundary and TA-18}
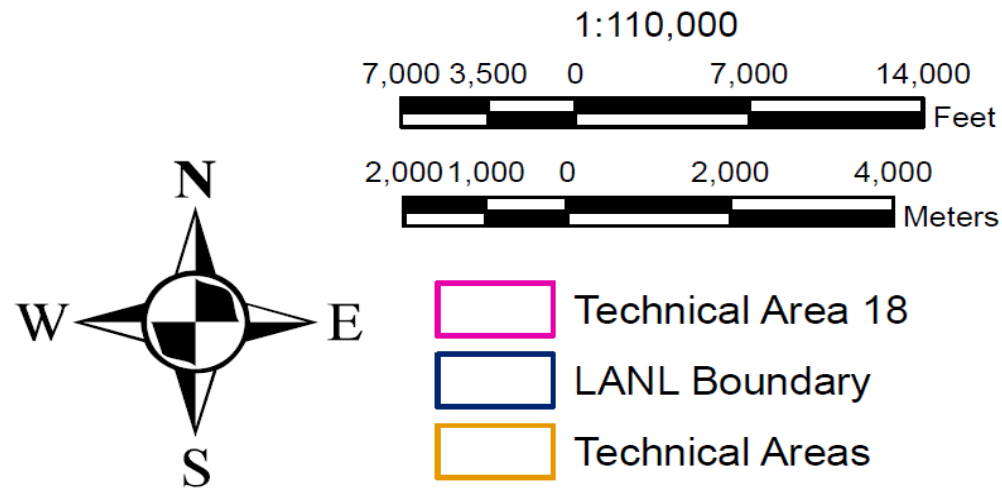

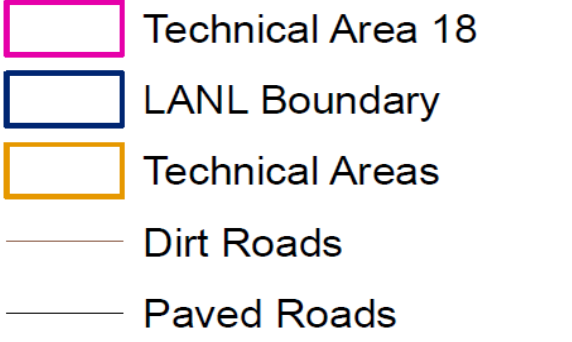

Figure 2: TA-18 location within LANL boundaries and in relation to Los Alamos town site (McGehee et al., 2009). 
In August 1943, Emilio Segre, a scientist and protégé of Enrico Fermi (renowned Manhattan Project scientist), and other fellow scientists comprising the P-5 Radioactivity group utilized the log buildings on the site (McGehee et al., 2009). The Pond cabin was used for both administrative functions as well as an occasional overnight sleeping quarters for the scientists; another cabin on the property was utilized for the P-5 experimental work, which contributed to the overall atomic bomb design, and was later torn down (McGehee et al., 2009). By 1944, the area was known as the Pajarito Canyon Laboratory, or the Pajarito Site, and had been taken over and expanded by the group referred to as G-3, in order to study the magnetic method of implosions as well as to conduct high explosive assembly testing with charges up to two tons (McGehee et al., 2009). For these tests, three firing sites were constructed, two of which were in the Pajarito site area; each consisted of at least one (or more) firing locations as well as aboveground "battleship” bunkers (including the historic TA-18-0002 battleship bunker) (McGehee et al., 2009). These bunkers were reinforced with steel plates (McGehee et al., 2009). These tests were conducted only up to the end of 1945 (McGehee et al., 2009).

In April 1946, the Pajarito site became the area where the Laboratory’s critical assembly work was conducted and this research was continued through the Cold War era (McGehee et al., 2009; "RFI Work," 1993). In response to a few criticality accidents that occurred at LANL, structures were constructed at Pajarito site so that criticality experiments could be assembled by machines which were controlled remotely and a safe distance away (McGehee et al., 2009). Throughout the early Cold War era (1946-1956), criticality experiments were conducted at Pajarito Site, providing the data needed to improve and confirm neutronic calculations that were critical for weapons design (McGehee et al., 2009). Overall, these experiments have greatly contributed to the nation's nuclear capacity (McGehee et al., 2009). In addition, in the 1970s and 
1980s, due to the facility capabilities on site and expertise in critical assembly work at Pajarito site, it became the nation's leading site for critical assembly safety training for the Department of Energy (DOE) as well as other institutions (McGehee et al., 2009; “RFI Work,” 1993).

Operations at the Pajarito Site have ceased and many of the facilities on the site have been, or are in the process of being, decontaminated, decommissioned, and demolished. However, four buildings at the site, including one of the battleship bunkers (TA-18-0002) and the historic Pond cabin (TA-18-0029), are being proposed as part of the Manhattan Project National Historic Park and need to be released for public access. Since both radiological materials as well as several chemicals and metals were used for the nuclear work that was conducted in the area, the four buildings need to be characterized by LANL's Associate Directorate for Environmental Safety and Health (ADESH) for radiological contamination, metals (especially beryllium, lead, and cadmium), organics, and asbestos.

The Pond cabin and the battleship bunker are not thought to have contamination; however, since health and safety controls were more flexible in the past, there may have been contamination brought into either building. In addition, workers lived in the Pond cabin on occasion while working at Pajarito site. There is evidence that a gentleman lived in the cabin for approximately 3 years while working at the site. It is possible, but unknown if, work materials may have been brought into the cabin by those living there. 


\subsection{PROJECT OBJECTIVES}

Presently, wet wipe sampling is listed as a housekeeping requirement of the U.S. Code of Federal Regulations Chronic Beryllium Disease Prevention Program 10 CFR 850 established in 1999; micro-vacuum sampling is not mentioned in the 1999 version of 10 CFR 850 (Department of Energy [DOE], 1999). Wet wipe sampling and micro-vacuuming are now being proposed to be included in the exposure monitoring requirements in the amended version of 10 CFR 850 via the 2016 DOE Notice of Proposed Rulemaking (DOE, 2016). There are two objectives of this study: 1) Compare the wet wipe and micro-vacuum sampling data to help form a technical basis for choosing between the two sampling methods; and 2) study the analytical results to determine if elemental soil constituents (beryllia, yttrium, etc.) can be used to distinguish between naturally-occurring elements and contamination from scientific operations. Both buildings have weathered for decades and have layers of dirt that may affect the results of metal contamination sampling surveys. Metal concentration ratios will be studied to distinguish between natural and man-made sources. Finally, the results of this project will help to improve the technical basis for interpreting surface contamination sampling results and determining protective actions including access control, personal protective equipment requirements, and housekeeping/decontamination efforts.

\subsection{BACKGROUND OF BERYLLIUM, CADMIUM, AND LEAD}

\subsection{HISTORY}

Beryllium is a naturally-occurring, light-weight alkaline metal that is found in the earth's crust (Klaasen, 2013). Due to its high tensile strength, beryllium is used in many applications including alloy production, computers, aeronautical brakes, electronics, dental bridges, aerospace, x-ray machines, nuclear weapons, nuclear reactors, etc. (Klaasen, 2013). Cadmium is a naturally-occurring transition metal (Klaasen, 2013). Cadmium is used in alloys, batteries, as a 
color pigment in paints and plastics, nuclear reactors, electroplating coatings, as well as many other applications (United States Department of Labor [USDOL], n.d.). Lead is a naturallyoccurring heavy metal that is found in the Earth's crust (USDOL, n.d.). Although it can occur naturally in the soil, it is only in small amounts and much of environmental lead is due to anthropogenic activities (Klaasen, 2013). Lead is easy to extract and to work with; batteries, radiation shields, ammunition and water pipes are examples of where lead-alloys are used (Klaasen, 2013). It is also used in automobile lead-acid storage batteries, ceramic glazes, ammunition, radiation shielding, plastics (USDOL, n.d.). Lead used to be added to interior and exterior household paints, gasoline, solder and water supply pipes but has been removed; lead in household paints was banned in 1977 due to it toxicity (USDOL, n.d.; Klaasen, 2013). Lead is also present in jewelry and pottery making, glass polishing, stained glass crafting, and gun smithing (Klaasen, 2013).

\subsection{TOXICOLOGY AND RELATED DISEASES}

The primary route of exposure for beryllium is inhalation, where it is absorbed into the blood slowly; dermal absorption, ocular absorption, or ingestion are other routes of exposure that can occur (Klaasen, 2013). Beryllium has a biological half-life of greater than a year, or approximately 450 days (Klaasen, 2013; “Beryllium (EHC 106, 1990),” n.d.). Beryllium exposure can lead to dermatitis, conjunctivitis, inflamed respiratory tract, acute chemical pneumonitis, chronic beryllium disease (CBD aka berylliosis), and lung cancer (Klaasen, 2013). Beryllium exposures can also cause a sensitization immune response; sensitized individuals can be identified through detection in the blood via a beryllium lymphocyte proliferation test (BeLPT) (CDC, 2011). When beryllium is inhaled, a significant portion of it is stored in the bone and the lungs, which contributes to CBD; however, beryllium can distribute to other organs in 
the body as well (Klaasen, 2013). Sensitized individuals can progress to develop CBD, where a combination of granulomas on the lungs coupled with fibrosis cause lung expansion difficulties, as well as blood oxygenation problems (CDC, 2011). Unfortunately, CBD can only be managed since there is not a cure (CDC, 2011).

Exposures for cadmium occur primarily via inhalation but can also occur through ingestion via contaminated food intake (USDOL, n.d.; Klaasen, 2013). If the soil is contaminated, then plants can readily accumulate it and can cause food and tobacco products to have a high cadmium content (Klaasen, 2013). Cadmium is highly toxic and exposures can lead to cancer or target many of the body’s different systems including cardiovascular, renal, gastrointestinal, neurological, reproductive and respiratory (USDOL, n.d.). Cadmium is a nephrotoxin and can cause renal injury; other toxic effects from exposure can cause chronic obstructive pulmonary disease, cardiovascular disease, osteoporosis, and has been associated with various cancers (Klaasen, 2013).

Lead exposure routes are through inhalation and ingestion (USDOL, n.d.). Usually inorganic lead exposure does not occur through dermal exposure absorption through the skin; however, ingestion can accidentally occur through contact with contaminated surfaces via hands and clothing and shoes (USDOL, n.d.). Ingestion is a big concern with infants and children due to hand to mouth contact from household dusts and paints (Klaasen, 2013). Lead toxicity can cause gastrointestinal, neurological, renal, hematologic, immunotoxicity, bone, and cardiovascular effects, as well as cancer; it also demonstrates a teratogenic effect to a pregnant woman’s fetus (USDOL, n.d.; Klaasen, 2013).

\subsection{REGULATIONS}

In 1999, DOE implemented the Chronic Beryllium Disease Prevention Program (also 
known as the Beryllium Rule 10 CFR 850) at all DOE facilities, which became effective in 2000, and imposed the following beryllium action levels: 1) $0.2 \mathrm{ug} / \mathrm{m}^{3}$ airborne limit, 2) a housekeeping limit for beryllium area surfaces of $3.0 \mathrm{ug} / 100 \mathrm{~cm}^{2}$, and 3) a housekeeping limit for non-beryllium work area surfaces of $0.2 \mathrm{ug} / 100 \mathrm{~cm}^{2}$, as well as for any equipment release (United States Department of Energy [DOE], 1999; Brisson \& Ekechukwu, 2009). Via this rule, surface and air monitoring are required in order to determine exposure levels and control effectiveness (DOE, 1999; Brisson \& Ekechukwu, 2009). At present, there is no surface housekeeping limit for cadmium. The surface housekeeping limit for lead that LANL uses follows the Housing of Urban Development (HUD) guidelines of $21.5 \mathrm{ug} / 100 \mathrm{~cm}^{2}$.

\subsection{MATERIALS AND METHODS}

\subsection{Sampling Design and Rationale}

Searches conducted in the LANL Industrial Hygiene database showed there was no characterization data entered for two of the four proposed park buildings at the Pajarito site, the Pond cabin and the battleship bunker. Dermal or inhalation exposures can occur from contaminated surface dust containing toxic metals, therefore, characterization of the buildings was needed prior to entry by the public. Due to upcoming tours that were scheduled with DOE as well as with NPS, Industrial Hygiene characterization sampling was needed in order to provide the tourists with safe entry requirements in regards to beryllium, lead, cadmium, and other metals.

As previously mentioned, TA-18-0002 is one of a few earth-covered bunkers referred to as "battleship bunkers" that were constructed to conduct magnetic method implosion tests and fullscale high explosive assembly tests in the area (McGehee et al., 2003). It is a 69 square foot building that is partially underground and is accessed by a concrete stairwell on the east side 
where the blast resistant steel door exists (McGehee et al., 2003). It is shielded inside with a steel plate on the west side (see Figure 3) (McGehee et al., 2003).

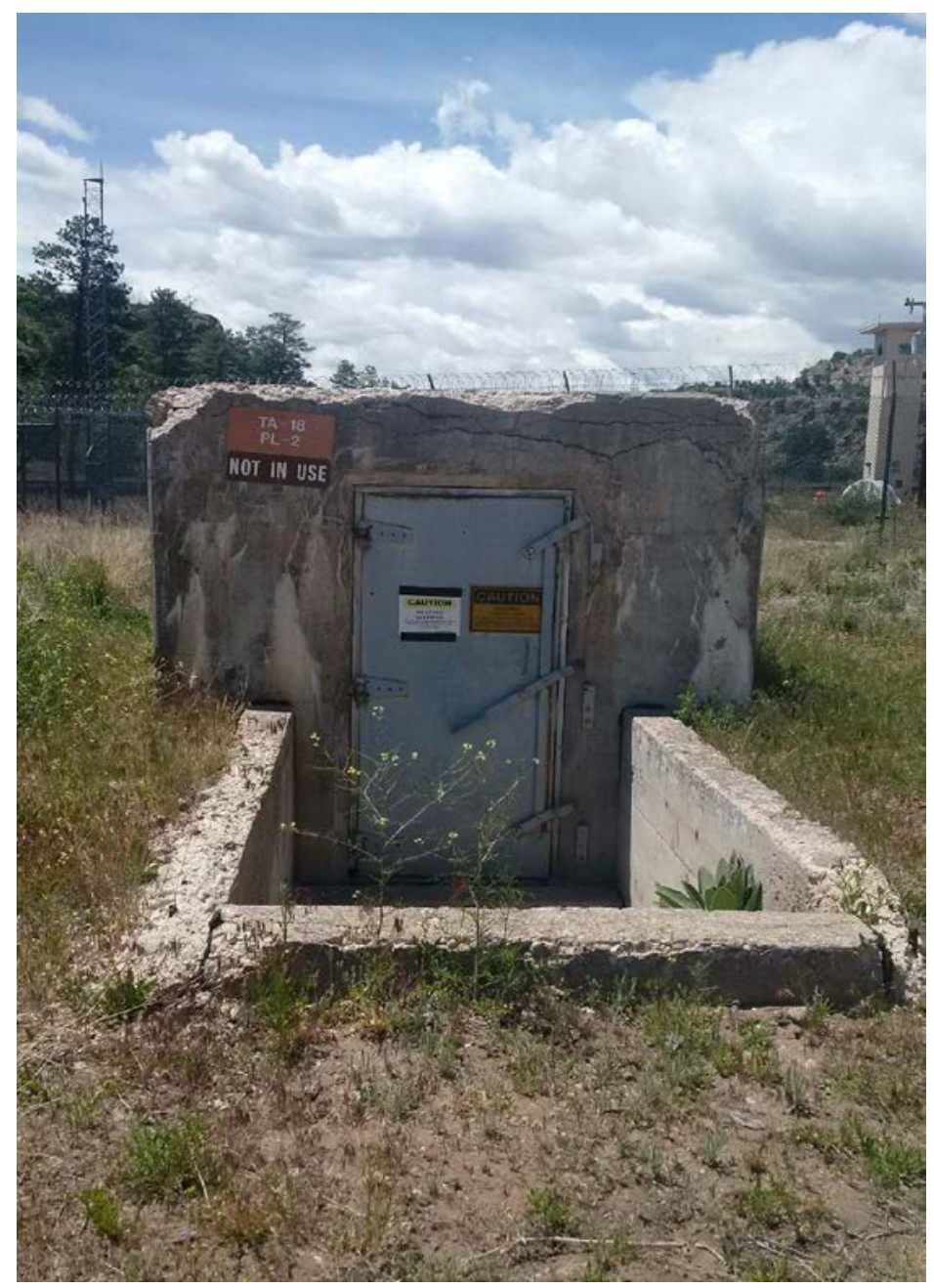

Figure 3: TA-18-0002 Battleship Bunker (ADC reviewed and approved by Audrey Martinez Z\#181899)

Since the Pond cabin (TA-18-0029) served as an occasional sleeping quarters for the scientists during the Manhattan Project and the Cold War era, it is suspected that experimental materials may have been brought into the cabin from time to time after work hours. However, officially it is documented as being used for both administrative functions as well as an occasional overnight sleeping quarters for the scientists (McGehee et al., 2009). It is a 384 square 
foot (16 x 24ft) building with an 8 foot high metal panel roof and log walls (see Figure 4)

(McGehee et al., 2003).

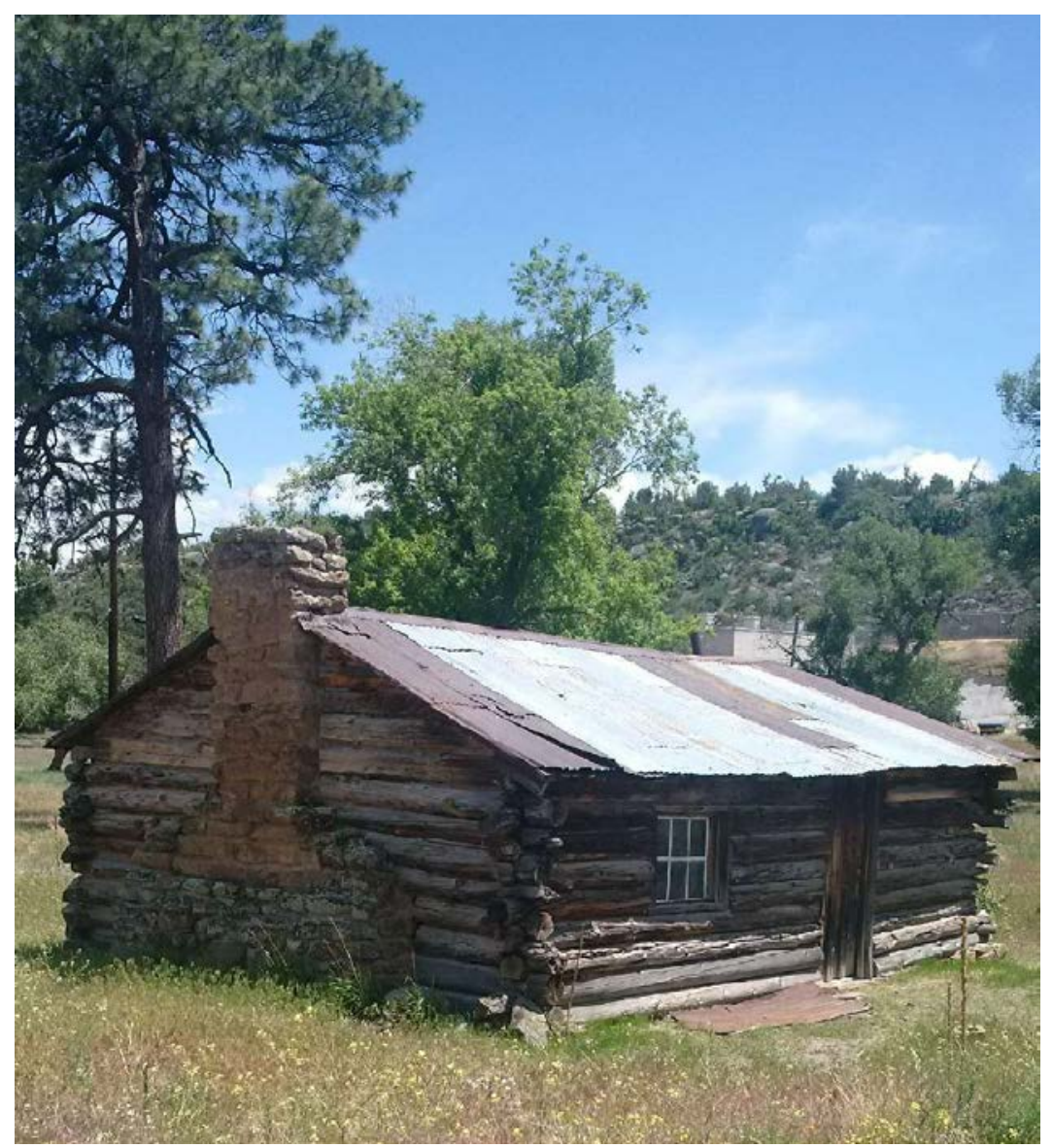

Figure 4: TA-18-0029 Pond Cabin (ADC reviewed and approved by Audrey Martinez Z\#181899)

These two buildings posed a different set of characterization concerns since: 1) the battleship bunker is encased in concrete and shielded in steel and has been exposed to the weather elements; and 2) the Pond Cabin, which is 102 years old and has been exposed to the weather elements as well, is of wood composition. This posed several questions about the validity of using the American Society for Testing and Materials (ASTM) D6966 "Standard Practice for Collection of Settled Dust Samples Using Wipe Sampling Methods for Subsequent Determination of Metals” protocol for these particular buildings due to the rough and porous 
surfaces of the wood and concrete. Using this protocol, ghost wipes are used to wipe a $10 \mathrm{~cm} \mathrm{x}$ $10 \mathrm{~cm}$ surface area; possible tears in the wipe from rough surfaces or mis-collection of dust in porous surfaces are possible limitations of using this method for rough and porous surfaces since it is recommended for smooth, nonporous surfaces (American Society for Testing Materials Standards [ASTM], 2013).

ASTM D7144 “Standard Practice for Collection of Surface Dust by Micro-Vacuum Sampling for Subsequent Metals Determination” protocol utilizes a micro-vacuum to collect surface dust and is applicable for rough or porous surfaces such as wood and concrete (ASTM, 2011). Using this process, an air sampling pump is connected to a cassette with a small collection hose attached and samples are "vacuumed" through the hose for a $100 \mathrm{~cm}^{2}$ surface area (ASTM, 2011). However, the micro-vacuum sampling technique has limitations as well including the fact that the technique biases towards particles that are smaller in size and less dense in weight and, therefore, will not reflect the total dust of the surface area (ASTM, 2011). In order to compare which method would be best to determine surface dust metal contamination levels for the buildings, side-by-side samples were collected in both building to compare the two methods.

\subsection{Field Methods and Procedures}

Sampling was conducted for two days in the TA-18 area by a team of 3 Industrial Hygiene Professionals at the battleship bunker on Day One and a team of 4 Industrial Hygiene Professionals and Technicians at the Pond cabin on Day Two. Due to the history of the area being involved in critical assembly work with nuclear materials and high explosive testing that was conducted near the battleship bunker, a National Institute for Occupational Safety and Health (NIOSH) 7300 Panel B metal sampling analysis was requested. NIOSH 7300 Panel B includes 27 metals: aluminum, arsenic, beryllium, cadmium, calcium, chromium, cobalt, copper, 
iron, lead, lithium, magnesium, manganese, molybdenum, nickel, phosphorus, platinum, selenium, silver, sodium, tellurium, thallium, titanium, vanadium, yttrium, zinc, and zirconium. This panel was chosen because it included key metals of interest including beryllium, cadmium, lead, aluminum, iron, and yttrium.

For sampling at the bunker building, the sampling team wore personal protective equipment (PPE) consisting of: Tyvek lab coats, booties, safety glasses, and nitrile gloves. For sampling at the Pond cabin, the sampling team wore PPE consisting of Tyvek suits, knee length booties with rubber soles, safety glasses, nitrile gloves, and an optional respirator with P100 cartridges (due to the presence of mice droppings in the cabin and their possible disturbance, with the concern being Hantavirus).

Fifteen wipe samples (including two blanks) plus fifteen micro-vacuum samples were taken at the battleship bunker. At the Pond cabin, twenty one wipe samples (including two blanks) plus twenty one micro-vacuum samples were taken. Wipe and micro-vacuum samples were taken side by side following $100 \mathrm{~cm}^{2}$ disposable templates that were made prior to sampling. Field notes were taken and a sketch of the sampled areas were logged into a logbook. See Figures 5 and 6 for sketches of sampled areas. Pictures were also taken of the sampled areas. See Figures 7A and 7B for pictures of the sampled areas of the Bunker building and Figures 8A and $8 \mathrm{~B}$ of the Pond cabin. 


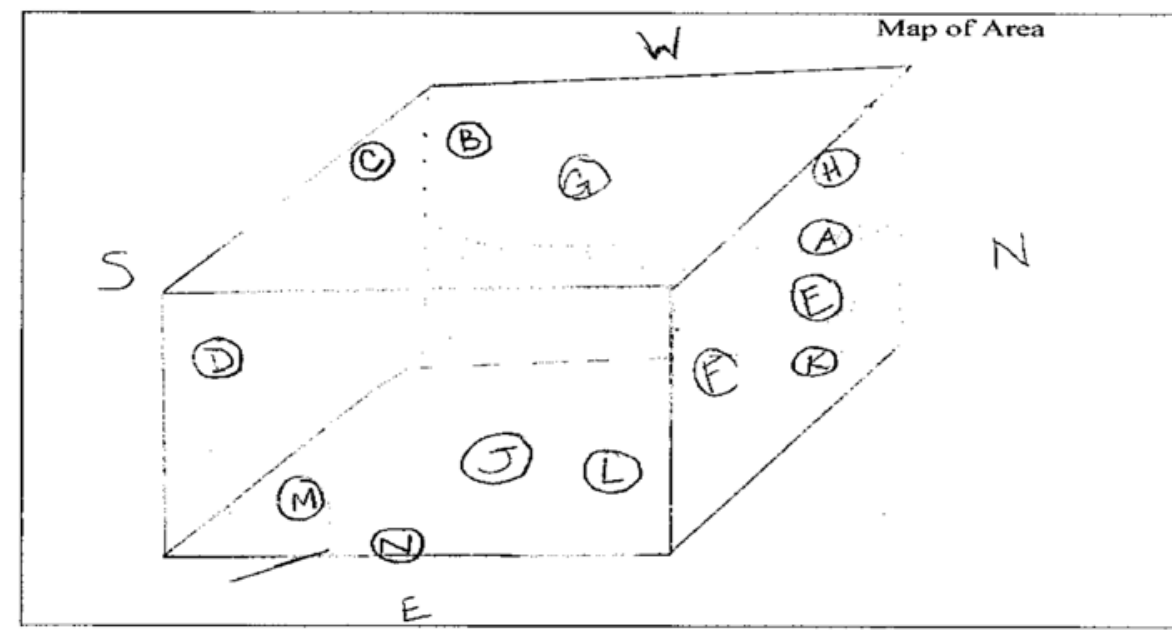

Figure 5: Sketch of the bunker building sampled areas.

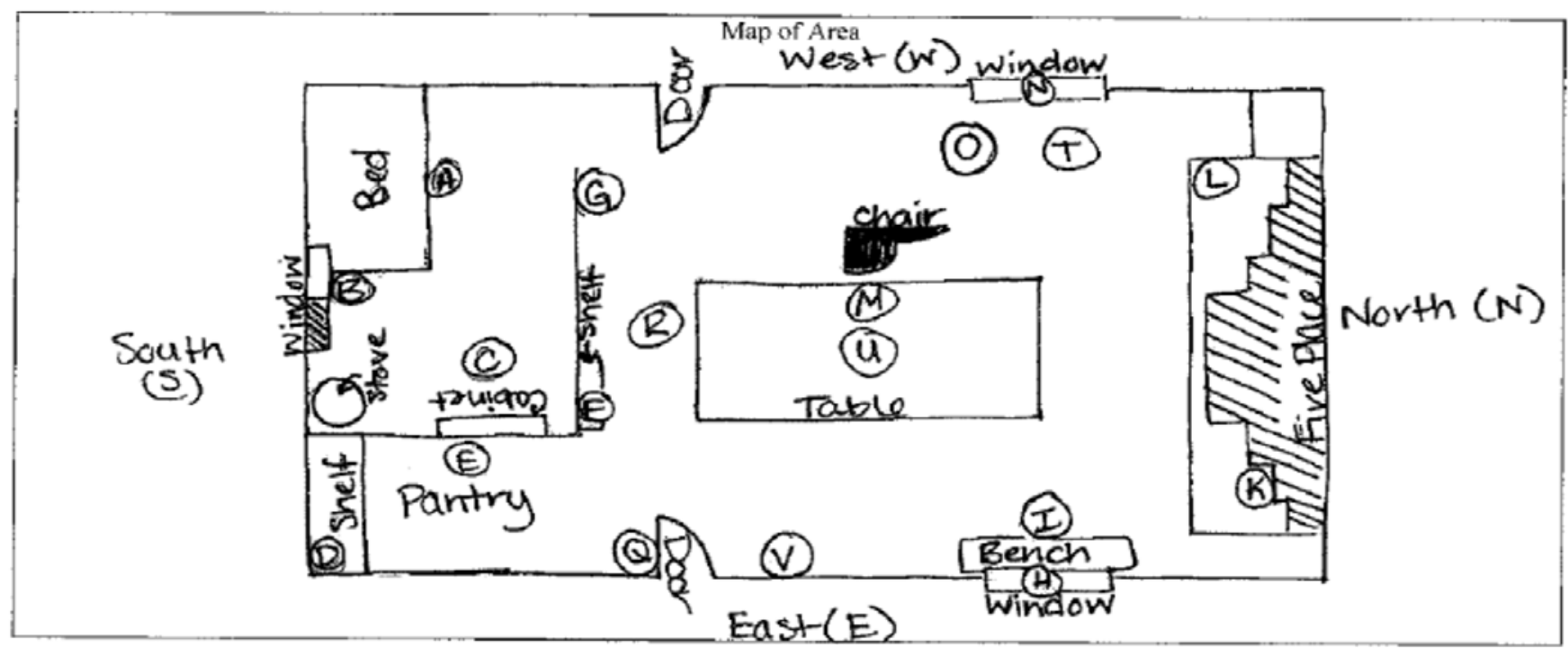

Figure 6: Sketch of the Pond cabin sampled areas. 

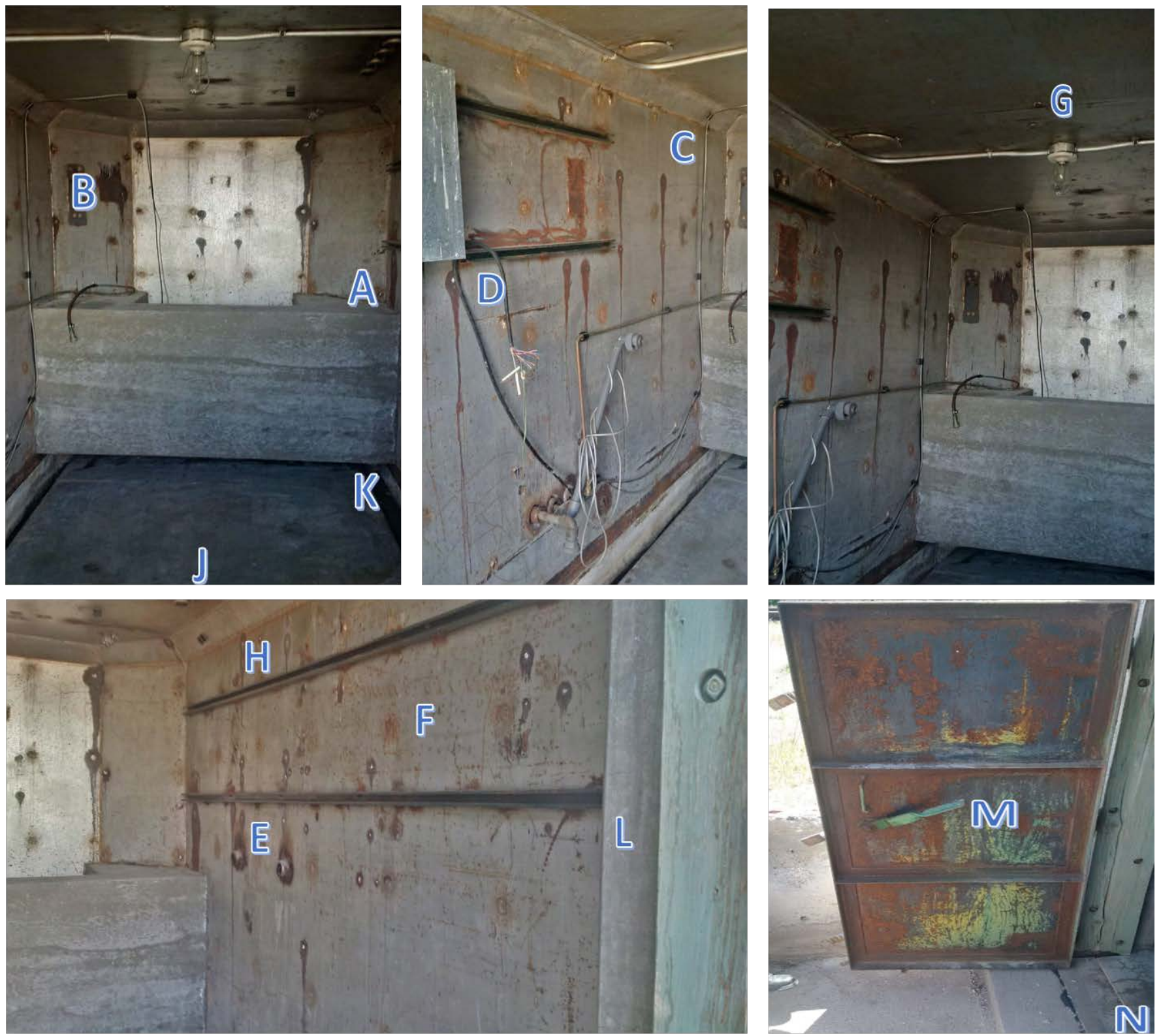

Top left: view of west wall. Top middle: view of south wall. Top right: view of ceiling. Bottom left: view of east wall. Bottom right: view of inside of east door.

Figure 7: Pictures of the bunker building sampled locations. 

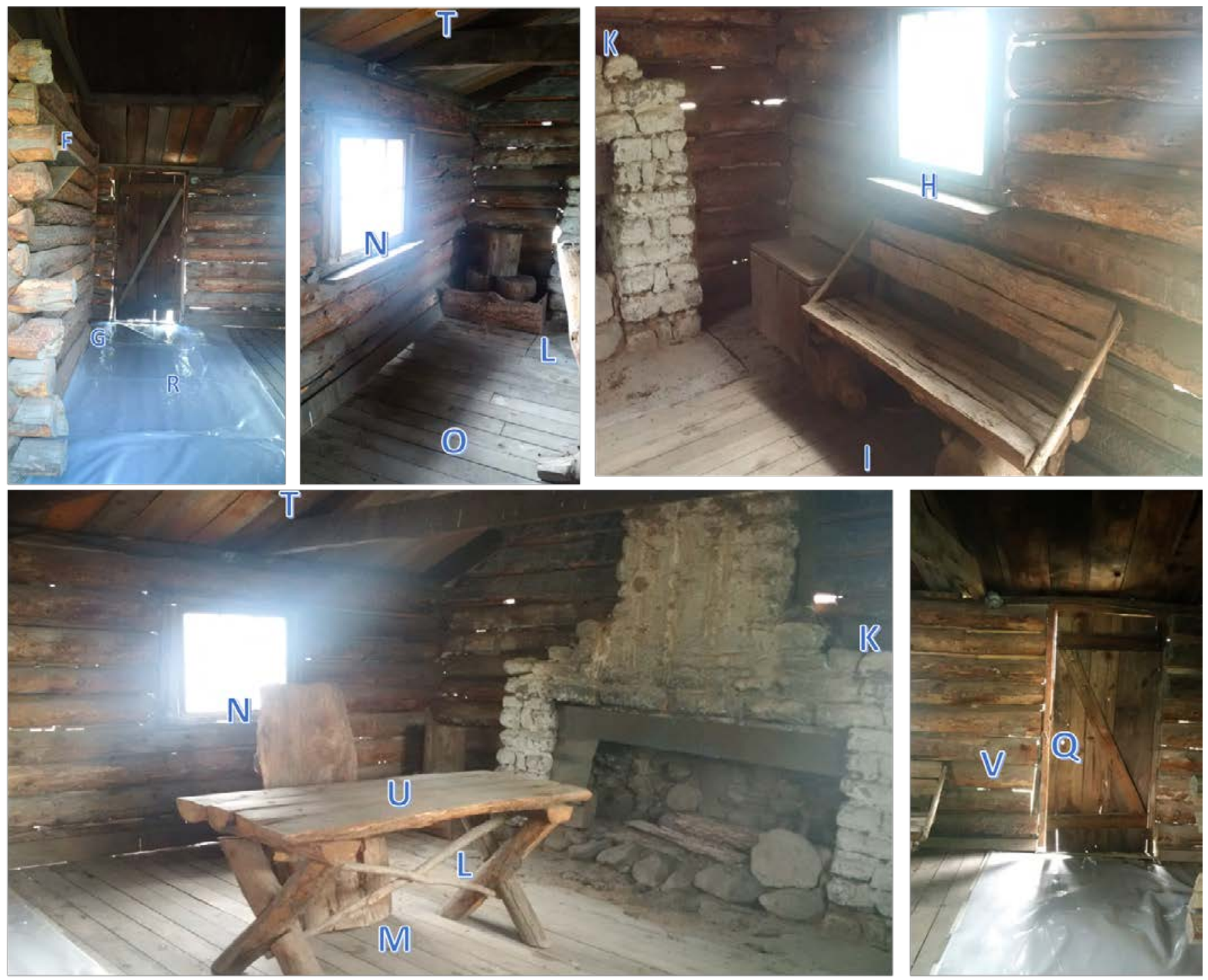

Top left: view of the west entrance. Top middle: view of the west side of the cabin. Top right: view of the east side of the cabin. Bottom left: view of the main room and west and north side of the cabin. Bottom right: view of the east entrance.

Figure 8A: Pictures of the main room of the Pond cabin sampled areas. 

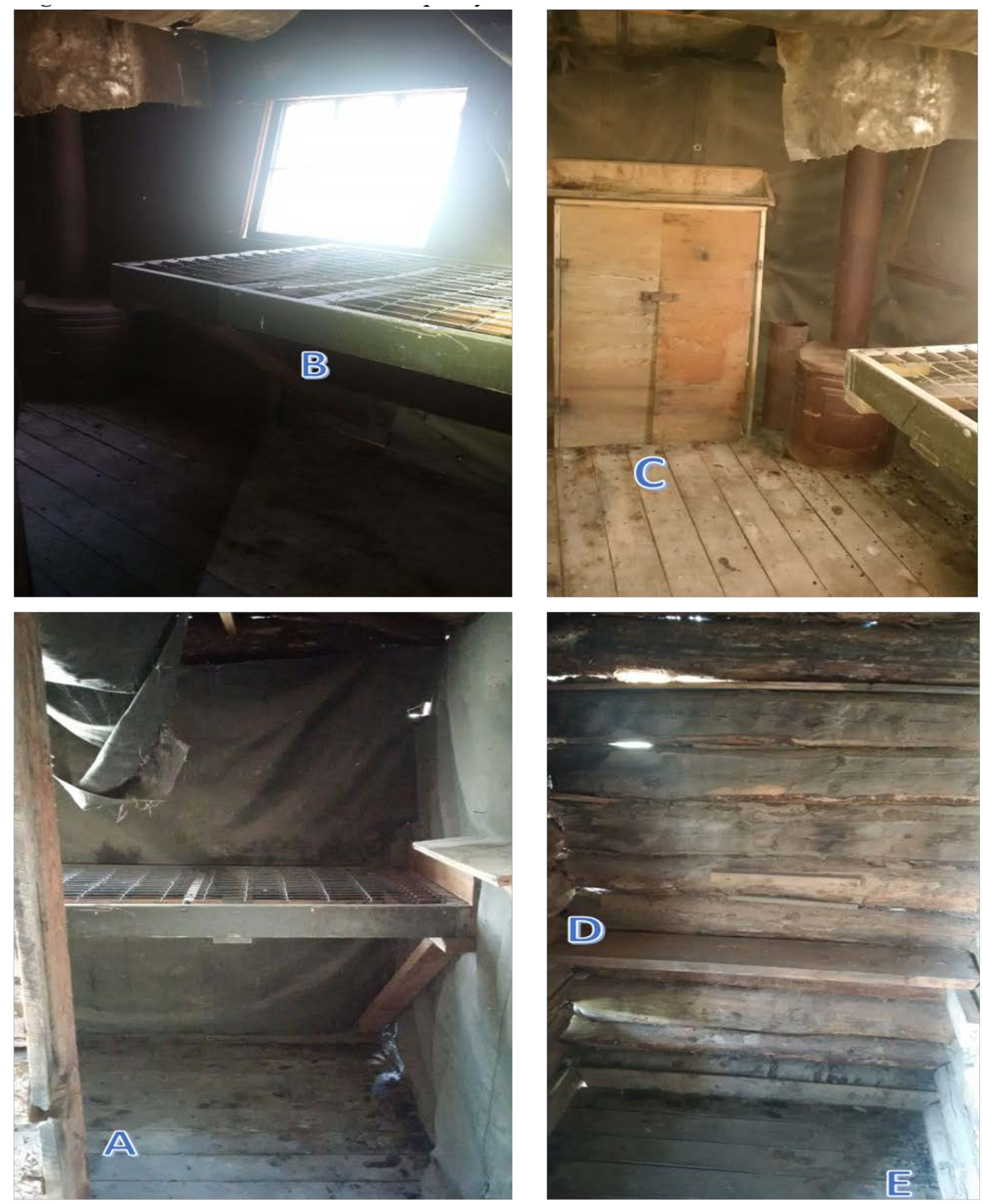

Top left: bedroom window and bed. Top right: bedroom stove and dresser cabinet. Bottom left: bed in the bedroom. Bottom right: pantry area.

Figure 8B: Pictures of the bedroom and pantry sampled areas of the Pond cabin. 
All samples collected were labeled with a pre-assigned, unique identification (ID) prior to sampling; micro-vacuum samples had an "MV" designation to begin the sampling ID and wipe samples had a "W". These letters were followed by the technical area number 18 and building number (either 02 or 29 depending on if it was the bunker building or the Pond cabin, respectively) and, lastly, alphabetical letters starting with A to designate each different sample.

Surface wipe samples were taken using the ASTM D6966 protocol (ASTM, 2013). Experimental Express ghost wipes that are pre-moistened with deionized water were utilized for the procedure because they were the most durable option for the surface composition. Clean, disposable nitrile gloves were donned and a ghost wipe was removed from its package, unfolded, and then folded in half. A $10 \mathrm{~cm} \times 10 \mathrm{~cm}$ area was wiped with firm pressure using a $100 \mathrm{~cm}^{2}$ template; horizontal s-strokes were done side-to-side, then without allowing the ghost wipe to touch anything else and folding the contaminant side in, s-strokes were done vertically, and then lastly, on the third fold, the edges of the sampled area were wiped. The wipe was then transferred into a pre-labeled Fisher $50 \mathrm{ml}$ centrifuge tube labeled with a unique sample ID and wrapped with a chain of custody seal. Gloves were changed after every surface wipe sample.

Micro-vacuum samples were taken in parallel to the surface wipe samples at each location using the ASTM D7144 protocol (ASTM, 2011). An Airchek Sampler pump was pre-calibrated with a Defender 510/520 calibration device to a flow rate of 2.5 LPM, per the ASTM D7144 procedure (ASTM, 2011). Small collection nozzles of Fisher polyvinyl (PVC) tygon tubing with an inside diameter of $0.60 \mathrm{~cm}$ were cut prior to sampling to a length of $5.5 \mathrm{~cm}$, with a $45^{\circ}$ angle cut at the inlet end (ASTM, 2011). The outlet end was fitted to a SKC pre-loaded, Mixed Cellulose Ester (MCE), matched weight filter cassette (0.8um pore size, $37 \mathrm{~mm}$ diameter, 3 piece, pre-banded - lot \#15651-7DF-014 Exp. 8/17) (ASTM, 2011). Each cassette was pre- 
labeled with a unique ID and had its own collection nozzle that was pre-fit in advance of sampling. PVC tygon tubing was used to connect the sampling pump to each cassette. A $10 \mathrm{~cm} \mathrm{x}$ $10 \mathrm{~cm}$ area was "vacuumed" in the same sampling manner as the wipe sampling, with the exception that vacuum samples were timed for one minute as per protocol (ASTM, 2011). The cassette was removed from the sampling pump apparatus and changed for each sample; the collection nozzle was thrown away and the nibs were placed back onto the end of the cassettes. A chain of custody seal was placed around the cassettes and each was placed into its own small plastic bag.

For both techniques, one field blank for approximately every ten samples was collected. The field blanks were treated the same way as the sample but no surface wiping or microvacuuming was conducted. Used PPE and disposable equipment was bagged and placed in the buildings until the results were analyzed, after which coordination of proper disposal was conducted with a LANL waste management coordinator.

A Chain-of-Custody form and a total of 72 samples were submitted for analysis to the Australian Laboratory Services (ALS) Environmental Laboratory in Salt Lake City, Utah (UT). ALS provides analytical services of environmental samples to LANL and is a National Environmental Laboratory Accreditation Conference (NELAC) and American Industrial Hygiene Association - Laboratory Accreditation Programs (AIHA-LAP) accredited laboratory. The NIOSH 7300 analysis with Panel B metals was requested which includes: Aluminum, Arsenic, Beryllium, Cadmium, Calcium, Chromium, Cobalt, Copper, Iron, Lead, Lithium, Magnesium, Manganese, Molybdenum, Nickel, Phosphorus, Platinum, Selenium, Silver, Sodium, Tellurium, Thallium, Titanium, Vanadium, Yttrium, Zinc, and Zirconium. For the micro-vacuum samples, total dust was also requested. 
The focus of the analysis is on the three main metals of interest (beryllium, cadmium, and lead) as well as aluminum, iron, and yttrium due to the past historical research and development projects that occurred at the site. Beryllium levels were compared to an internal LANL housekeeping limit of $0.2 \mathrm{ug} / 100 \mathrm{~cm}^{2}$ and lead levels were compared to the LANL limit of 21.5 ug $/ 100 \mathrm{~cm}^{2}$. Cadmium and all other Panel B metals were analyzed for their presence, however, there is no internal housekeeping limits for these metals to be compared to.

\subsection{Results and Discussion}

\subsection{Comparison Statistics of Micro-vacuum vs. Wet Wipe Sampling}

To compare the micro-vacuum and wet wipe techniques statistically, beryllium (Be) and lead $(\mathrm{Pb})$ values for both techniques were used because these were the only two metals out of the Panel B metal scan that had LANL internal housekeeping limits to compare the values to. As noted previously, LANL follows an internal housekeeping limit $0.2 \mathrm{ug} / 100 \mathrm{~cm}^{2}$ for beryllium surface contamination and the U.S. Department of Housing and Urban Development (HUD) limit of $21.5 \mathrm{ug} / 100 \mathrm{~cm}^{2}$ for lead surface contamination.

As summarized in Table I, at the bunker building, thirteen side-by-side micro-vacuum and wet wipe samples were taken. The limit of detection (LOD), which is basically non-detection of the metals, for beryllium and lead were 0.0021 and $0.38 \mathrm{ug} / \mathrm{sample}$, respectively, for the wipe samples and 0.0038 and $0.38 \mathrm{ug} / \mathrm{sample}$, respectively, for the micro-vacuum samples. For the micro-vacuum technique, the beryllium and lead maximum values were 0.0074 and 5.7 $\mathrm{ug} / 100 \mathrm{~cm}^{2}$, respectively, versus the wet wipe technique maximum beryllium and lead values of 0.016 and $510 \mathrm{ug} / 100 \mathrm{~cm}^{2}$. For the micro-vacuum technique, $69.2 \%$ of the beryllium samples had values less than the LOD, 30.8\% were between the LOD and the reporting limit (RL) of 0.013 ug/sample, and none were above the RL. For the wet wipe technique, 38.5\% of the beryllium 
samples had values less than the LOD, 15.4\% were between the LOD and the RL of 0.0071

ug/sample, and $46.2 \%$ were above the RL. None of the micro-vacuum or wet wipe samples had values at or above the DOE internal housekeeping limit of $0.2 \mathrm{ug} / 100 \mathrm{~cm}^{2}$.

The lead data showed the same trend as the beryllium data in that for the micro-vacuum technique, $61.5 \%$ of the lead values were less than the LOD, 23.1\% were between the LOD and the RL of $1.3 \mathrm{ug} / \mathrm{sample}$, and $15.4 \%$ were above the RL. For the wet wipe technique, $7.7 \%$ of the lead values were between the LOD and the RL of $1.3 \mathrm{ug} / \mathrm{sample}$, and $92.3 \%$ of the values were above the RL. In addition, the wet wipe technique found that $46.2 \%$ of the samples indicated that there is lead contamination at or above the HUD limit of $21.5 \mathrm{ug} / 100 \mathrm{~cm}^{2}$ as compared to none of the micro-vacuum samples.

\section{Table I: Bunker Building Micro-vacuum vs. Wet Wipe Comparison}

\begin{tabular}{|c|c|c|c|c|c|c|c|c|}
\hline \multirow[t]{3}{*}{$\mathrm{Be}$} & Analysis & $\mathrm{N}^{*}$ & Minimum & Maximum & $\mathbf{N}<\mathbf{L O D}(\mathbf{N} / \%)$ & $\begin{array}{c}\mathbf{L O D}<\mathbf{N}<\mathbf{R L} \\
(\mathbf{N} / \%)\end{array}$ & $\begin{array}{l}\mathbf{N}>\mathbf{R L} \\
(\mathbf{N} / \%)\end{array}$ & $\mathrm{N} \geq 0.2 \mathrm{ug} / 100 \mathrm{~cm}^{2}(\mathrm{~N} / \%)$ \\
\hline & $\begin{array}{l}\text { Micro- } \\
\text { vacuum }\end{array}$ & 13 & LOD & 0.0074 & $9(69.2 \%)$ & $4(30.8 \%)$ & $0(0 \%)$ & $0(0 \%)$ \\
\hline & Wipes & 13 & LOD & 0.016 & $5(38.5 \%)$ & $2(15.4 \%)$ & $6(46.2 \%)$ & $0(0 \%)$ \\
\hline \multirow[t]{3}{*}{$\mathrm{Pb}$} & Analysis & $\mathbf{N}^{*}$ & Minimum & Maximum & $\mathrm{N}<\mathrm{LOD}(\mathrm{N} / \%)$ & $\mathrm{LOD}<\mathrm{N}<\mathrm{RL}$ & $\begin{array}{l}\mathbf{N}>\mathbf{R L} \\
(\mathrm{N} / \%)\end{array}$ & $\begin{array}{c}\mathrm{N} \geq 21.5 \mathrm{ug} / 100 \mathrm{~cm}^{2} \\
(\mathrm{~N} / \%)\end{array}$ \\
\hline & $\begin{array}{l}\text { Micro- } \\
\text { vacuum }\end{array}$ & 13 & LOD & 5.7 & $8(61.5 \%)$ & $3(23.1 \%)$ & $2(15.4 \%)$ & $0(0 \%)$ \\
\hline & Wipes & 13 & LOD & 510 & $0(0 \%)$ & $1(7.7 \%)$ & $12(92.3 \%)$ & $6(46.2 \%)$ \\
\hline
\end{tabular}

*excludes field blanks

Note: The LOD for Be was $0.0038 \mathrm{ug} / \mathrm{sample}$ for the micro-vacuum samples and $0.0021 \mathrm{ug} / \mathrm{sample}$ for the wipe samples. The LOD for $\mathrm{Pb}$ for the micro-vacuum and wipe samples was $0.38 \mathrm{ug} / \mathrm{sample}$. The RL for Be for the micro-vacuum samples was $0.013 \mathrm{ug} / \mathrm{sample}$ and $0.0071 \mathrm{ug} / \mathrm{sample}$ for the wipes. The RL for Pb for the microvacuum and wipe samples was $1.3 \mathrm{ug} / \mathrm{sample.}$

A two-tailed paired t-test was run for the beryllium data from the Bunker building for both techniques (see Table II). The t-test probability was 0.02 , indicating that the two techniques are statistically different. The t-test was also run for aluminum ( $\mathrm{Al})$ and iron (Fe), since these two metals are commonly found in soil constituents; the t-test probability for aluminum also indicated that the two techniques are statistically different but the probability for iron did not. 
Table II: Bunker Building Micro-vacuum vs. Wet Wipe Comparison

\begin{tabular}{|c|c|c|c|c|}
\hline Be & $\mathbf{N} *$ & $\begin{array}{c}\text { Mean } \\
\left(\mathbf{u g} / 100 \mathrm{~cm}^{2}\right)\end{array}$ & $\begin{array}{l}\text { Standard } \\
\text { deviation }\end{array}$ & $\begin{array}{l}\text { Probability for Paired } \\
2 \text { tail t-test }\end{array}$ \\
\hline Micro-vacuum & 13 & 0.0017 & 0.0028 & \multirow[t]{2}{*}{0.0209} \\
\hline Wipes & 13 & 0.0070 & 0.0067 & \\
\hline $\mathbf{A l}$ & $\mathbf{N} *$ & $\begin{array}{c}\text { Mean } \\
\left(\mathbf{u g} / 100 \mathrm{~cm}^{2}\right)\end{array}$ & $\begin{array}{l}\text { Standard } \\
\text { deviation }\end{array}$ & $\begin{array}{c}\text { Probability for Paired } \\
2 \text { tail t-test }\end{array}$ \\
\hline Micro-vacuum & 13 & 9.4 & 16.29 & \multirow[t]{2}{*}{0.0230} \\
\hline Wipes & 13 & 706.92 & 980.96 & \\
\hline Fe & $\mathbf{N *}$ & $\begin{array}{c}\text { Mean } \\
\left(\mathbf{u g} / 100 \mathrm{~cm}^{2}\right)\end{array}$ & $\begin{array}{l}\text { Standard } \\
\text { deviation }\end{array}$ & $\begin{array}{c}\text { Probability for Paired } \\
2 \text { tail t-test }\end{array}$ \\
\hline Micro-vacuum & 13 & 218.03 & 422.25 & \multirow[t]{2}{*}{0.0985} \\
\hline Wipes & 13 & 7396.15 & 14845.04 & \\
\hline
\end{tabular}

*excludes field blanks

As summarized in Table III, nineteen side-by-side micro-vacuum and wet wipe samples were taken at the Pond cabin, excluding the two field blanks. The minimum value for beryllium and lead for both techniques is the limit of detection (LOD). For the micro-vacuum technique, the beryllium and lead maximum values were 0.039 and $3 \mathrm{ug} / 100 \mathrm{~cm}^{2}$, respectively, versus the wet wipe technique maximum beryllium and lead values of $0.31 \mathrm{ug} / 100 \mathrm{~cm}^{2}$ and 150 ug/ $100 \mathrm{~cm}^{2}$. For the micro-vacuum technique, $68.4 \%$ of the beryllium samples had values less than the LOD, 26.3\% were between the LOD and the reporting limit (RL), and 5.3\% were above the RL. For the wet wipe technique, $100 \%$ of the beryllium samples had values above the RL. Moreover, none of the micro-vacuum samples had values at or above the DOE internal housekeeping limit of $0.2 \mathrm{ug} / 100 \mathrm{~cm}^{2}$ but $36.8 \%$ of the wet wipe samples did. The lead data showed the same trend as beryllium in that for the micro-vacuum technique, $89.4 \%$ of the lead values were less than the LOD, 5.3\% were between the LOD and the RL, and 5.3\% were above the RL. For the wet wipe technique, 5.3\% of the lead values were between the LOD and the RL and $94.7 \%$ of the values were above the RL. In addition, the wet wipe technique found that 
$52.6 \%$ of the samples indicated that there is lead contamination at or above the HUD limit of $21.5 \mathrm{ug} / 100 \mathrm{~cm}^{2}$ as compared to none of the micro-vacuum samples with lead values above the HUD.

Table III: Pond Cabin Micro-vacuum vs. Wet Wipe Comparison

\begin{tabular}{|c|c|c|c|c|c|c|c|c|}
\hline \multirow[t]{3}{*}{$\mathrm{Be}$} & Analysis & $N^{*}$ & Minimum & Maximum & $\mathrm{N}<\mathrm{LOD}(\mathrm{N} / \%)$ & $\begin{array}{c}\text { LOD }<\mathrm{N}<\mathrm{RL} \\
(\mathrm{N} / \%)\end{array}$ & $\begin{array}{l}\mathrm{N}>\mathrm{RL} \\
(\mathrm{N} / \%)\end{array}$ & $\mathrm{N} \geq 0.2 \mathrm{ug} / 100 \mathrm{~cm}^{2}(\mathrm{~N} / \%)$ \\
\hline & $\begin{array}{l}\text { Micro- } \\
\text { vacuum }\end{array}$ & 19 & LOI) & 0.039 & $13(68.4 \%)$ & $5(26.3 \%)$ & $1(5.3 \%)$ & $0(0 \%)$ \\
\hline & Wipes & 19 & LOI) & 0.31 & $0(0 \%)$ & $0(0 \%)$ & $19(100 \%)$ & $7(36.8 \%)$ \\
\hline \multirow[t]{3}{*}{$\mathrm{Pb}$} & Analysis & $\mathrm{N}^{*}$ & Minimum & Maximum & $\mathrm{N}<\mathrm{LOD}(\mathrm{N} / \%)$ & $\mathrm{LOD}<\mathrm{N}<\mathrm{RL}$ & $\begin{array}{l}\mathbf{N}>\mathbf{R L} \\
(\mathbf{N} / \%)\end{array}$ & $\mathrm{N} \geq 21.5 \mathrm{ug} / 100 \mathrm{~cm}^{2}(\mathrm{~N} / \%)$ \\
\hline & $\begin{array}{l}\text { Micro- } \\
\text { vacuum }\end{array}$ & 19 & LOD & 3 & $17(89.4 \%)$ & $1(5.3 \%)$ & $1(5.3 \%)$ & $0(0 \%)$ \\
\hline & Wipes & 19 & LOD & 150 & $0(0 \%)$ & $1(5.3 \%)$ & $18(94.7 \%)$ & $10(52.6 \%)$ \\
\hline
\end{tabular}

*excludes field blanks

Note: The LOD for Be was 0.0038 ug/sample for the micro-vacuum samples and $0.0021 \mathrm{ug} / \mathrm{sample}$ for the wipe samples. The LOD for $\mathrm{Pb}$ for the micro-vacuum and wipe samples was $0.38 \mathrm{ug} / \mathrm{sample}$. The RL for Be for the micro-vacuum samples was $0.013 \mathrm{ug} / \mathrm{sample}$ and $0.0071 \mathrm{ug} / \mathrm{sample}$ for the wipes. The RL for $\mathrm{Pb}$ for the microvacuum and wipe samples was $1.3 \mathrm{ug} / \mathrm{sample}$.

As seen in Table IV, a two-tailed paired t-test was run with the beryllium data from the Pond cabin for both techniques. The t-test probability for the Pond cabin for beryllium was $4.226 \times 10^{-8}$, which is less than 0.05 , indicating that the two techniques are statistically different. The t-test was also done for the Aluminum and Iron values, since these are constituents commonly found in soil and the probabilities revealed the same conclusion that the two techniques are statistically different. 
Table IV: Pond Cabin Micro-vacuum vs. Wet Wipe Comparison

\begin{tabular}{|c|c|c|c|c|}
\hline $\mathbf{B e}$ & $\mathbf{N *}$ & $\begin{array}{c}\text { Mean } \\
\left(\mathrm{ug} / 100 \mathrm{~cm}^{2}\right)\end{array}$ & $\begin{array}{l}\text { Standard } \\
\text { deviation }\end{array}$ & $\begin{array}{c}\text { Probability for Paired } \\
2 \text { tail t-test }\end{array}$ \\
\hline Micro-vacuum & 19 & 0.0037 & 0.0090 & \multirow[t]{2}{*}{$4.226 \times 10^{-8}$} \\
\hline Wipes & 19 & 0.1535 & 0.0758 & \\
\hline $\mathbf{A l}$ & $\mathbf{N}^{*}$ & $\begin{array}{c}\text { Mean } \\
\left(\mathrm{ug} / 100 \mathrm{~cm}^{2}\right)\end{array}$ & $\begin{array}{l}\text { Standard } \\
\text { deviation }\end{array}$ & $\begin{array}{c}\text { Probability for Paired } \\
2 \text { tail t-test }\end{array}$ \\
\hline Micro-vacuum & 19 & 27.832 & 83.210 & \multirow[t]{2}{*}{$8.867 \times 10^{-9}$} \\
\hline Wipes & 19 & 1590 & 713.92 & \\
\hline $\mathbf{F e}$ & $\mathbf{N}^{*}$ & $\begin{array}{c}\text { Mean } \\
\left(\mathrm{ug} / 100 \mathrm{~cm}^{2}\right)\end{array}$ & $\begin{array}{l}\text { Standard } \\
\text { deviation }\end{array}$ & $\begin{array}{c}\text { Probability for Paired } \\
2 \text { tail t-test }\end{array}$ \\
\hline Micro-vacuum & 19 & 31.668 & 101.57 & \multirow[t]{2}{*}{$1.595 \times 10^{-7}$} \\
\hline Wipes & 19 & 1732.1 & 813.73 & \\
\hline
\end{tabular}

*excludes field blanks

This data indicates that the two techniques are statistically different for both buildings and, through a comparison of the percentages on beryllium and lead values alone, the data indicates that the wet wipes were a more efficient method of sampling than the micro-vacuum. However, in the comparative statistics data with the bunker building, the iron probability indicated that the two methods are not statistically different because the micro-vacuum technique was able to detect a sufficient amount of iron as compared to the wet wipe technique. Iron is a heavier metal in density than aluminum and beryllium therefore, this is probably not attributed to weight but may be attributed to the composition of the surface in the bunker building. The bunker building is a steel structure encased in concrete and iron is one of the elements that composes steel. As evidenced in the pictures in Figure 7, there are several areas where there is obvious rust on the steel walls, therefore, this may attribute to the higher iron seen in both the micro-vacuum and wipe samples for the bunker building as compared to the Pond cabin. 


\subsection{Determination of Background Beryllium Levels Due to the Soil vs. Operational Contamination}

As seen in Table III, the wet wipe technique showed that seven samples taken at the Pond cabin had levels of beryllium at or slightly above $0.2 \mathrm{ug} / 100 \mathrm{~cm}^{2}$, which is the DOE internal housekeeping limit that LANL follows. This raised concerns that beryllium contamination existed in the Pond cabin. However, there were seven locations sampled whose values ranged from 0.2 to $0.31 \mathrm{ug} / 100 \mathrm{~cm}^{2}$. Since the values were so close to the internal housekeeping limit of $0.2 \mathrm{ug} / 100 \mathrm{~cm}^{2}$, the question was raised if it is possible that the beryllium levels were due to background soil or whether it was operational contamination. A provision in the DOE Beryllium Rule states that background beryllium levels from the soil can be subtracted if they are known (DOE, 1999; Brisson \& Ekechukwu, 2009). However, there is not data for the Pajarito site in particular and comparison of the background levels to other areas around Los Alamos County may not be sufficient since the levels could vary depending on the operational history in other areas.

Prokisch, Kovacs, Palencscar, Szegvari, and Gyori (2000) used an “yttrium normalization method" to determine if high concentrations of elements like chromium that occur naturally in the soil are due to background levels or contamination; since both exist in the soil naturally, a non-contaminated area should have a strong concentration correlation (Prokisch, Kovacs, Palencscar, Szegvari, \& Gyori, 2000). Yttrium and chromium concentrations were compared through linear regression plots to determine background versus contamination and they saw that they were strongly correlated; this yttrium normalization technique can be applied to other common elements of the soil as well (Prokisch et al., 2000). At other DOE sites, yttrium and beryllium concentrations have been compared to determine whether or not beryllium 


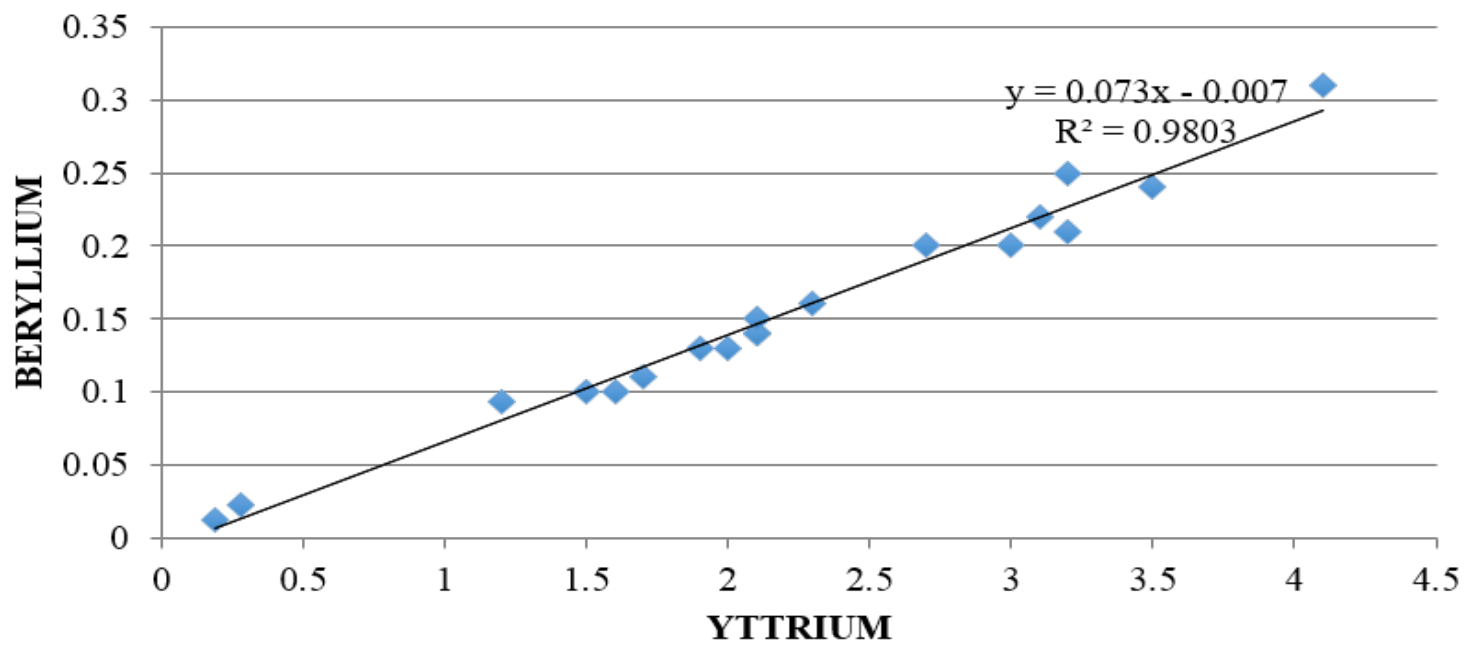

Figure 9: Yttrium vs. Beryllium Linear Regression Plot

concentrations were due to background or operational contamination. Using this method, the yttrium and beryllium concentrations were compared for the Pond Cabin wet wipe samples.

The yttrium versus beryllium concentrations from the Pond cabin were plotted in a scatter plot with yttrium on the $\mathrm{x}$ axis and beryllium on the $\mathrm{y}$ axis (Figure 9). A linear regression line was run through the values and the equation and the r-squared values were determined. The rsquared value for these data was 0.98 , indicating a strong correlation between the yttrium and beryllium concentrations found at the Pond cabin. Therefore, it was determined that the beryllium levels are due to background soil.

\subsection{Presence of $\mathrm{Pb}$ and $\mathrm{Cd}$}

As seen in Tables I and III, both the bunker building and the Pond cabin had wipe samples with lead concentrations above the HUD limit of $21.5 \mathrm{ug} / 100 \mathrm{~cm}^{2}$. These levels above the HUD ranged from $28-150 \mathrm{ug} / 100 \mathrm{~cm}^{2}$ for 6 samples at the bunker and $22-150 \mathrm{ug} / 100 \mathrm{~cm}^{2}$ for the 10 samples at the Pond cabin. Unlike the beryllium concentrations that were very close to or slightly above the housekeeping limit, these concentrations were high enough that it was unlikely that they were due to background concentrations.

For cadmium, there is not currently a defined housekeeping limit for surface dust sampling but it was taken into consideration whether or not cadmium was present. For the wipe samples, 
twelve of the thirteen samples taken (92.3\%) at the Bunker building had concentrations above the RL; seventeen of the nineteen samples taken (89.5\%) at the Pond cabin had concentrations above the reporting limit. Therefore, cadmium is present in both buildings.

\subsection{Conclusions}

In conclusion, it was determined from this sampling project that the wet wipe surface sampling technique is more efficient in its ability to collect metal concentrations from surface dust and had results in statistically significant higher concentrations than the micro-vacuum sampling technique. However, this may be specific for this scenario in which both buildings had weathered and sat with basically no activity for several decades; it is possible there may have been layers of grime or oil on the surfaces that the micro-vacuum technique had difficulty penetrating. As indicated by Brisson and Ekechukwu (2009), to do proper surface sampling, it is essential to determine the surface characteristics of the areas to be sampled (ie. porosity and roughness) as well as the surface dust characteristics (thickness, oiliness) as these play a role in selection of the proper surface sampling technique (Brisson \& Ekechukwu, 2009). The porosity and roughness of the wood and concrete were considered in selecting the micro-vacuum technique but the thickness and oiliness of the dust was not considered as well.

Currently, DOE is revising its DOE Notice of Proposed Rulemaking and Public Comment for 10 CFR 850 guidelines and they suggest micro-vacuum sampling as a method that can be used for exposure monitoring. This data suggests that the sampling methods are not strongly correlated and that results may not be comparable. It is pertinent that until there is more known about the efficiency of the micro-vacuum technique in different scenarios, it should not be recommended as a solo method to determine possible surface dust contamination levels. 
As a result of the beryllium concentrations found in the Pond cabin that were slightly above the internal housekeeping limit, LANL is currently gathering information from other sources and compiling a "white paper" on how to statistically determine whether or not beryllium levels are due to operational or background contamination. As stated above, the yttrium normalization method has been used at other DOE sites to determine operational vs background contamination. However, there is not an official document that has been compiled to support this. This project has propelled LANL to propose new industrial hygiene and statistically-proven methods for determination of background versus operational contamination.

Due to the lead contamination and presence of cadmium at both buildings, PPE and administrative controls have been put in place for incoming DOE and NPS tourists. PPE for entry into the Pond cabin and the bunker building now requires booties and gloves. However, currently the Pond cabin is lined from the east to the west entrance with plastic so that tourists can visually tour, but not touch, the inside of the Pond cabin; this allows LANL to minimize the waste generated from these tours. In addition, signage about the lead contamination has been posted at both buildings. Future decontamination efforts will have to be implemented before public entry without PPE can be granted. 


\subsection{References}

American Society for Testing Materials Standards (ASTM) (2013). (American Society for Testing Materials Standards) “ASTM D6966-13 Standard Practice for Collection of Settled Dust Samples Using Wipe Sampling Methods for Subsequent Determination of Metals.”

American Society for Testing Materials Standards (ASTM) (2011). (American Society for Testing Materials Standards) “ASTM D7144-05a (Reapproved 2011) Standard Practice for Collection of Surface Dust by Micro-vacuum Sampling for Subsequent Metals Determination.”

Beryllium (EHC 106, 1990). Retrieved July 20, 2016, from http://www.inchem.org/documents/ehc/ehc/ehc106.htm

Brisson, M. J., \& Ekechukwu, A. A. (Ed.) (2009). Beryllium: Environmental Analysis and Monitoring. Cambridge, UK: Royal Society of Chemistry.

CDC. (2011, May 18). BERYLLIUM. Retrieved July 21, 2016, from http://www.cdc.gov/niosh/topics/beryllium/be-sensitization-drds.html

Klaasen, C.D. (Ed.). (2013). Casarett \& Doull's Toxicology The Basic Science of Poisons (8th ed.). McGraw-Hill Education.

LANL (Los Alamos National Laboratory) 1993. RFI Work Plan for Operable Unit 1093. LAUR-93-422. Los Alamos National Laboratory, Los Alamos, New Mexico.

Manhattan Project National Historical Park https://www.nps.gov/mapr/index.htm (accessed May 1, 2016)

McGehee ED, McCarthy S, Towery K, Ronquillo J, Garcia KLM, and Isaacson J. 2003. Sentinels of the Atomic Dawn. Historic Building Survey Report No. 215, LA-UR03-0726. On file at ENV-EAQ, Los Alamos National Laboratory, Los Alamos, New Mexico.

McGehee ED, Garcia KLM, McCarthy S, Loomis E, Towery K, Ronquillo J, Naranjo N, and Honig K. 2009. Of Critical Importance: An Assessment of Historic Buildings at Pajarito Site (TA-18). Historic Building Survey Report No. 291, LA-UR-09-03456. On file at ENV-EAQ, Los Alamos National Laboratory, Los Alamos, New Mexico.

Prokisch J, Kovacs B, Palencsar A, Szegvari I, and Gyori Z. 2000. Yttrium Normalisation: A New Tool For Detection of Chromium Contamination in Soil Samples. Environmental Geochemistry and Health 22: 317-323.

UNITED STATES DEPARTMENT OF LABOR. (n.d.). Retrieved June 23, 2016, from https://www.osha.gov/SLTC/cadmium/

UNITED STATES DEPARTMENT OF LABOR. (n.d.). Retrieved June 23, 2016, 
from https://www.osha.gov/SLTC/lead/

10 CFR Part 850 Chronic Beryllium Disease Prevention Program, 64 Department of Energy § 850 (1999).

10 CFR Part 850 Chronic Beryllium Disease Prevention Program; Proposed Rule, 81 Department of Energy § 850 (2016). 
8.0 Appendix A: Raw Data (Note: Blanks are highlighted in yellow.)

\begin{tabular}{|c|c|c|c|c|c|}
\hline \multicolumn{6}{|c|}{ TA-18-0002 Micro-vacuum vs. Wet Wipe Sampling Data Comparison } \\
\hline CAS \# & Analyte & Sample ID & Result (ug/sample or ug/ $100 \mathrm{~cm}^{2}$ ) & Sample ID & Result (ug/sample or ug/ $100 \mathrm{~cm}^{2}$ ) \\
\hline 7429-90-5 & Aluminum & \multirow{6}{*}{ MV1802A } & {$[3.4]$} & \multirow{6}{*}{ W1802A } & \begin{tabular}{|c|}
280 \\
\end{tabular} \\
\hline 7440-41-7 & Beryllium & & {$[0.0060]$} & & 0.013 \\
\hline 7440-43-9 & Cadmium & & $<0.023$ & & 0.33 \\
\hline 7439-89-6 & Iron & & 8.4 & & 660 \\
\hline 7439-92-1 & Lead & & 1.4 & & 420 \\
\hline $7440-65-5$ & Yttrium & & $<0.023$ & & 0.18 \\
\hline 7429-90-5 & Aluminum & \multirow{6}{*}{ MV1802B } & [3.1] & \multirow{6}{*}{ W1802B } & 630 \\
\hline $7440-41-7$ & Beryllium & & $<0.0038$ & & [0.0041] \\
\hline 7440-43-9 & Cadmium & & $<0.023$ & & 0.75 \\
\hline 7439-89-6 & Iron & & 30 & & 2500 \\
\hline 7439-92-1 & Lead & & $<0.38$ & & 15 \\
\hline $7440-65-5$ & Yttrium & & $<0.023$ & & {$[0.043]$} \\
\hline 7429-90-5 & Aluminum & \multirow{6}{*}{ MV1802C } & {$[4.6]$} & \multirow{6}{*}{ W1802C } & 340 \\
\hline 7440-41-7 & Beryllium & & {$[0.0074]$} & & 0.012 \\
\hline 7440-43-9 & Cadmium & & $<0.023$ & & 0.25 \\
\hline $7439-89-6$ & Iron & & 25 & & 920 \\
\hline 7439-92-1 & Lead & & $<0.38$ & & 11 \\
\hline $7440-65-5$ & Yttrium & & $<0.023$ & & 0.15 \\
\hline 7429-90-5 & Aluminum & \multirow{6}{*}{ MV1802D } & 57 & \multirow{6}{*}{ W1802D } & 3600 \\
\hline 7440-41-7 & Beryllium & & [0.0044] & & $<0.0021$ \\
\hline $7440-43-9$ & Cadmium & & $<0.023$ & & 1.3 \\
\hline 7439-89-6 & Iron & & 750 & & 20000 \\
\hline 7439-92-1 & Lead & & {$[0.43]$} & & 33 \\
\hline $7440-65-5$ & Yttrium & & $<0.023$ & & $<0.023$ \\
\hline $7429-90-5$ & Aluminum & \multirow{6}{*}{ MV1802E } & 31 & \multirow{6}{*}{ W1802E } & 1700 \\
\hline 7440-41-7 & Beryllium & & $<0.0038$ & & 0.016 \\
\hline 7440-43-9 & Cadmium & & 0.11 & & 8.4 \\
\hline 7439-89-6 & Iron & & 470 & & 2100 \\
\hline 7439-92-1 & Lead & & $<0.38$ & & 19 \\
\hline $7440-65-5$ & Yttrium & & $<0.023$ & & {$[0.070]$} \\
\hline $7429-90-5$ & Aluminum & \multirow{6}{*}{ MV1802F } & 5.9 & \multirow{6}{*}{ W1802F } & 1100 \\
\hline 7440-41-7 & Beryllium & & $<0.0038$ & & $<0.0021$ \\
\hline 7440-43-9 & Cadmium & & $<0.023$ & & 0.67 \\
\hline 7439-89-6 & Iron & & 110 & & 11000 \\
\hline 7439-92-1 & Lead & & $<0.38$ & & 10 \\
\hline $7440-65-5$ & Yttrium & & $<0.023$ & & [0.033] \\
\hline 7429-90-5 & Aluminum & \multirow{6}{*}{ MV1802G } & $<1.5$ & \multirow{6}{*}{ W1802G } & 150 \\
\hline 7440-41-7 & Beryllium & & $<0.0038$ & & $<0.0021$ \\
\hline $7440-43-9$ & Cadmium & & $<0.023$ & & 1 \\
\hline 7439-89-6 & Iron & & 7.3 & & 1300 \\
\hline $7439-92-1$ & Lead & & $<0.38$ & & [1.0] \\
\hline $7440-65-5$ & Yttrium & & $<0.023$ & & $<0.023$ \\
\hline
\end{tabular}




\begin{tabular}{|c|c|c|c|c|c|}
\hline $7429-90-5$ & Aluminum & \multirow{6}{*}{$\mathrm{MV} 1802 \mathrm{H}$} & [3.5] & \multirow{6}{*}{ W1802H } & 420 \\
\hline 7440-41-7 & Beryllium & & $<0.0038$ & & $<0.0021$ \\
\hline 7440-43-9 & Cadmium & & {$[0.071]$} & & 28 \\
\hline 7439-89-6 & Iron & & 17 & & 3400 \\
\hline 7439-92-1 & Lead & & $<0.38$ & & 2.7 \\
\hline $7440-65-5$ & Yttrium & & $<0.023$ & & $<0.023$ \\
\hline 7429-90-5 & Aluminum & \multirow{6}{*}{ MV1802I } & $<1.5$ & \multirow{6}{*}{ W1802I } & {$[2.0]$} \\
\hline 7440-41-7 & Beryllium & & $<0.0038$ & & $<0.0021$ \\
\hline 7440-43-9 & Cadmium & & $<0.023$ & & $<0.023$ \\
\hline 7439-89-6 & Iron & & $<1.5$ & & {$[5.5]$} \\
\hline 7439-92-1 & Lead & & $<0.38$ & & $<0.38$ \\
\hline $7440-65-5$ & Yttrium & & $<0.023$ & & $<0.023$ \\
\hline 7429-90-5 & Aluminum & \multirow{6}{*}{ MV1802J } & {$[2.1]$} & \multirow{6}{*}{ W1802J } & 170 \\
\hline $7440-41-7$ & Beryllium & & $<0.0038$ & & 0.01 \\
\hline 7440-43-9 & Cadmium & & $<0.023$ & & 0.31 \\
\hline 7439-89-6 & Iron & & {$[3.7]$} & & 250 \\
\hline 7439-92-1 & Lead & & {$[0.45]$} & & 28 \\
\hline $7440-65-5$ & Yttrium & & $<0.023$ & & 0.14 \\
\hline $7429-90-5$ & Aluminum & \multirow{6}{*}{ MV1802K } & {$[2.1]$} & \multirow{6}{*}{ W1802K } & 240 \\
\hline 7440-41-7 & Beryllium & & $<0.0038$ & & 0.016 \\
\hline 7440-43-9 & Cadmium & & $<0.023$ & & 0.85 \\
\hline 7439-89-6 & Iron & & [3.5] & & 450 \\
\hline 7439-92-1 & Lead & & {$[0.46]$} & & 97 \\
\hline $7440-65-5$ & Yttrium & & $<0.023$ & & 0.25 \\
\hline $7429-90-5$ & Aluminum & \multirow{6}{*}{ MV1802L } & {$[2.0]$} & \multirow{6}{*}{ W1802L } & 150 \\
\hline 7440-41-7 & Beryllium & & $<0.0038$ & & [0.0053] \\
\hline $7440-43-9$ & Cadmium & & $<0.023$ & & 0.48 \\
\hline 7439-89-6 & Iron & & [3.0] & & 180 \\
\hline 7439-92-1 & Lead & & $<0.38$ & & 8.2 \\
\hline $7440-65-5$ & Yttrium & & $<0.023$ & & 0.076 \\
\hline 7429-90-5 & Aluminum & \multirow{6}{*}{ MV1802M } & [3.7] & \multirow{6}{*}{ W1802M } & 180 \\
\hline 7440-41-7 & Beryllium & & [0.0045] & & $<0.021$ \\
\hline 7440-43-9 & Cadmium & & $<0.023$ & & {$[0.32]$} \\
\hline 7439-89-6 & Iron & & 1400 & & 53000 \\
\hline 7439-92-1 & Lead & & 5.7 & & 510 \\
\hline $7440-65-5$ & Yttrium & & $<0.023$ & & $<0.023$ \\
\hline $7429-90-5$ & Aluminum & \multirow{6}{*}{ MV1802N } & {$[2.3]$} & \multirow{6}{*}{ W1802N } & 230 \\
\hline 7440-41-7 & Beryllium & & $<0.0038$ & & 0.014 \\
\hline $7440-43-9$ & Cadmium & & $<0.023$ & & 0.32 \\
\hline $7439-89-6$ & Iron & & 6.5 & & 390 \\
\hline 7439-92-1 & Lead & & $<0.38$ & & 37 \\
\hline $7440-65-5$ & Yttrium & & $<0.023$ & & 0.2 \\
\hline $7429-90-5$ & Aluminum & \multirow{6}{*}{ MV18020 } & $<1.5$ & \multirow{6}{*}{ W18020 } & 10 \\
\hline 7440-41-7 & Beryllium & & $<0.0038$ & & $<0.0021$ \\
\hline 7440-43-9 & Cadmium & & $<0.023$ & & $<0.023$ \\
\hline 7439-89-6 & Iron & & [1.7] & & {$[5.8]$} \\
\hline 7439-92-1 & Lead & & $<0.38$ & & $<0.38$ \\
\hline $7440-65-5$ & Yttrium & & $<0.023$ & & $<0.023$ \\
\hline
\end{tabular}




\begin{tabular}{|c|c|c|c|c|c|}
\hline \multicolumn{6}{|c|}{ TA-18-0029 Micro-vacuum vs. Wipe Result Comparison } \\
\hline CAS Number & Analyte Name & Sample ID & Result (ug/sample or ug/ $100 \mathrm{~cm}^{2}$ ) & Sample ID & Result (ug/sample or ug/100cm2) \\
\hline $7429-90-5$ & Aluminum & \multirow{6}{*}{ MV1829A } & \begin{tabular}{|c|}
{$[3.7]$} \\
\end{tabular} & \multirow{6}{*}{ W1829A } & 2000 \\
\hline $7440-41-7$ & Beryllium & & $<0.0038$ & & 0.21 \\
\hline $7440-43-9$ & Cadmium & & $<0.023$ & & 0.26 \\
\hline $7439-89-6$ & Iron & & {$[3.7]$} & & 2400 \\
\hline $7439-92-1$ & Lead & & $<0.38$ & & 30 \\
\hline $7440-65-5$ & Yttrium & & $<0.023$ & & 3.2 \\
\hline $7429-90-5$ & Aluminum & \multirow{6}{*}{ MV1829B } & 12 & \multirow{6}{*}{ W1829B } & 1200 \\
\hline $7440-41-7$ & Beryllium & & $<0.0038$ & & 0.14 \\
\hline $7440-43-9$ & Cadmium & & $<0.023$ & & 0.89 \\
\hline $7439-89-6$ & Iron & & 14 & & 1200 \\
\hline $7439-92-1$ & Lead & & {$[0.42]$} & & 150 \\
\hline $7440-65-5$ & Yttrium & & $<0.023$ & & 2.1 \\
\hline $7429-90-5$ & Aluminum & \multirow{6}{*}{ MV1829C } & 7.7 & \multirow{6}{*}{ W1829C } & 1800 \\
\hline 7440-41-7 & Beryllium & & $<0.0038$ & & 0.2 \\
\hline $7440-43-9$ & Cadmium & & $<0.023$ & & 0.32 \\
\hline 7439-89-6 & Iron & & 8.4 & & 2500 \\
\hline $7439-92-1$ & Lead & & $<0.38$ & & 36 \\
\hline $7440-65-5$ & Yttrium & & $<0.023$ & & 3 \\
\hline 7429-90-5 & Aluminum & \multirow{6}{*}{ MV1829D } & 370 & \multirow{6}{*}{ W1829D } & 2900 \\
\hline $7440-41-7$ & Beryllium & & 0.039 & & 0.31 \\
\hline 7440-43-9 & Cadmium & & $<0.023$ & & 0.26 \\
\hline 7439-89-6 & Iron & & 450 & & 3200 \\
\hline 7439-92-1 & Lead & & 3 & & 22 \\
\hline $7440-65-5$ & Yttrium & & 0.61 & & 4.1 \\
\hline 7429-90-5 & Aluminum & \multirow{6}{*}{ MV1829E } & 7.3 & \multirow{6}{*}{ W1829E } & 2200 \\
\hline 7440-41-7 & Beryllium & & $<0.0038$ & & 0.24 \\
\hline $7440-43-9$ & Cadmium & & $<0.023$ & & 0.44 \\
\hline 7439-89-6 & Iron & & 6 & & 2400 \\
\hline $7439-92-1$ & Lead & & $<0.38$ & & 34 \\
\hline 7440-65-5 & Yttrium & & $<0.023$ & & 3.5 \\
\hline 7429-90-5 & Aluminum & \multirow{6}{*}{ MV1829F } & [3.7] & \multirow{6}{*}{ W1829F } & 1200 \\
\hline 7440-41-7 & Beryllium & & {$[0.0077]$} & & 0.11 \\
\hline $7440-43-9$ & Cadmium & & $<0.023$ & & 0.94 \\
\hline 7439-89-6 & Iron & & 5.9 & & 1300 \\
\hline 7439-92-1 & Lead & & $<0.38$ & & 15 \\
\hline $7440-65-5$ & Yttrium & & $<0.023$ & & 1.7 \\
\hline 7429-90-5 & Aluminum & \multirow{6}{*}{ MV1829G } & 9.9 & \multirow{6}{*}{ W1829G } & 1000 \\
\hline $7440-41-7$ & Beryllium & & {$[0.0050]$} & & 0.1 \\
\hline 7440-43-9 & Cadmium & & $<0.023$ & & 0.16 \\
\hline 7439-89-6 & Iron & & 7.6 & & 1100 \\
\hline 7439-92-1 & Lead & & $<0.38$ & & 14 \\
\hline $7440-65-5$ & Yttrium & & $<0.023$ & & 1.5 \\
\hline 7429-90-5 & Aluminum & \multirow{6}{*}{ MV1829H } & {$[2.5]$} & \multirow{6}{*}{$\mathrm{W} 1829 \mathrm{H}$} & 1700 \\
\hline 7440-41-7 & Beryllium & & $<0.0038$ & & 0.16 \\
\hline 7440-43-9 & Cadmium & & $<0.023$ & & 0.63 \\
\hline 7439-89-6 & Iron & & {$[3.4]$} & & 2000 \\
\hline 7439-92-1 & Lead & & $<0.38$ & & 79 \\
\hline $7440-65-5$ & Yttrium & & $<0.023$ & & 2.3 \\
\hline
\end{tabular}




\begin{tabular}{|c|c|c|c|c|c|}
\hline 7429-90-5 & Aluminum & \multirow{6}{*}{ MV1829I } & 22 & \multirow{6}{*}{ W1829I } & 1400 \\
\hline $7440-41-7$ & Beryllium & & {$[0.0039]$} & & 0.14 \\
\hline 7440-43-9 & Cadmium & & $<0.023$ & & 0.21 \\
\hline 7439-89-6 & Iron & & 22 & & 1500 \\
\hline 7439-92-1 & Lead & & $<0.38$ & & 19 \\
\hline $7440-65-5$ & Yttrium & & {$[0.036]$} & & 2.1 \\
\hline 7429-90-5 & Aluminum & \multirow{6}{*}{ MV1829J } & $<1.5$ & \multirow{6}{*}{ W1829J } & {$[2.6]$} \\
\hline 7440-41-7 & Beryllium & & $<0.0038$ & & $<0.0021$ \\
\hline $7440-43-9$ & Cadmium & & $<0.023$ & & $<0.023$ \\
\hline \begin{tabular}{|l|}
$7439-89-6$ \\
\end{tabular} & Iron & & $<1.5$ & & {$[4.9]$} \\
\hline \begin{tabular}{|l|}
$7439-92-1$ \\
\end{tabular} & Lead & & $<0.38$ & & $<0.38$ \\
\hline 7440-65-5 & Yttrium & & $<0.023$ & & $<0.023$ \\
\hline 7429-90-5 & Aluminum & \multirow{6}{*}{ MV1829K } & 11 & \multirow{6}{*}{ W1829K } & 2600 \\
\hline $7440-41-7$ & Beryllium & & $<0.0038$ & & 0.25 \\
\hline $7440-43-9$ & Cadmium & & $<0.023$ & & {$[0.068]$} \\
\hline 7439-89-6 & Iron & & 9.6 & & 2800 \\
\hline \begin{tabular}{|l|}
$7439-92-1$ \\
\end{tabular} & Lead & & $<0.38$ & & 12 \\
\hline 7440-65-5 & Yttrium & & $<0.023$ & & 3.2 \\
\hline 7429-90-5 & Aluminum & \multirow{6}{*}{ MV1829L } & 34 & \multirow{6}{*}{ W1829L } & 1500 \\
\hline 7440-41-7 & Beryllium & & $<0.0038$ & & 0.13 \\
\hline 7440-43-9 & Cadmium & & $<0.023$ & & 0.086 \\
\hline 7439-89-6 & Iron & & 32 & & 1400 \\
\hline 7439-92-1 & Lead & & $<0.38$ & & 11 \\
\hline $7440-65-5$ & Yttrium & & [0.049] & & 1.9 \\
\hline $7429-90-5$ & Aluminum & \multirow{6}{*}{ MV1829M } & {$[4.7]$} & \multirow{6}{*}{ W1829M } & 2600 \\
\hline 7440-41-7 & Beryllium & & $<0.0038$ & & 0.22 \\
\hline $7440-43-9$ & Cadmium & & $<0.023$ & & 0.24 \\
\hline 7439-89-6 & Iron & & {$[3.9]$} & & 2600 \\
\hline \begin{tabular}{|l|}
$7439-92-1$ \\
\end{tabular} & Lead & & $<0.38$ & & 31 \\
\hline \begin{tabular}{|l|}
$7440-65-5$ \\
\end{tabular} & Yttrium & & $<0.023$ & & 3.1 \\
\hline \begin{tabular}{|l|}
$7429-90-5$ \\
\end{tabular} & Aluminum & \multirow{6}{*}{ MV1829N } & 6.6 & \multirow{6}{*}{ W1829N } & 1000 \\
\hline \begin{tabular}{|l|}
$7440-41-7$ \\
\end{tabular} & Beryllium & & {$[0.0079]$} & & 0.093 \\
\hline $7440-43-9$ & Cadmium & & $<0.023$ & & 0.2 \\
\hline 7439-89-6 & Iron & & 5.7 & & 1100 \\
\hline 7439-92-1 & Lead & & $<0.38$ & & 38 \\
\hline \begin{tabular}{|l|}
$7440-65-5$ \\
\end{tabular} & Yttrium & & $<0.023$ & & 1.2 \\
\hline \begin{tabular}{|l}
$7429-90-5$ \\
\end{tabular} & Aluminum & \multirow{6}{*}{ MV18290 } & 10 & \multirow{6}{*}{ W18290 } & 2100 \\
\hline \begin{tabular}{|l|}
$7440-41-7$ \\
\end{tabular} & Beryllium & & {$[0.0060]$} & & 0.2 \\
\hline 7440-43-9 & Cadmium & & $<0.023$ & & 0.25 \\
\hline 7439-89-6 & Iron & & 8.9 & & 2400 \\
\hline 7439-92-1 & Lead & & $<0.38$ & & 45 \\
\hline $7440-65-5$ & Yttrium & & $<0.023$ & & 2.7 \\
\hline \begin{tabular}{|l|}
$7429-90-5$ \\
\end{tabular} & Aluminum & \multirow{6}{*}{ MV1829Q } & {$[1.6]$} & \multirow{6}{*}{ W1829Q } & 160 \\
\hline 7440-41-7 & Beryllium & & $<0.0038$ & & 0.012 \\
\hline \begin{tabular}{|l|}
$7440-43-9$ \\
\end{tabular} & Cadmium & & $<0.023$ & & 0.11 \\
\hline \begin{tabular}{|l|}
$7439-89-6$ \\
\end{tabular} & Iron & & {$[1.8]$} & & 190 \\
\hline 7439-92-1 & Lead & & $<0.38$ & & 2.6 \\
\hline $7440-65-5$ & Yttrium & & $<0.023$ & & 0.19 \\
\hline \begin{tabular}{|l|}
$7429-90-5$ \\
\end{tabular} & Aluminum & \multirow{6}{*}{ MV1829R } & {$[4.2]$} & \multirow{6}{*}{ W1829R } & 1500 \\
\hline \begin{tabular}{|l|}
$7440-41-7$ \\
\end{tabular} & Beryllium & & $<0.0038$ & & 0.13 \\
\hline \begin{tabular}{|l|}
$7440-43-9$ \\
\end{tabular} & Cadmium & & $<0.023$ & & 0.25 \\
\hline \begin{tabular}{|l|}
$7439-89-6$ \\
\end{tabular} & Iron & & {$[3.7]$} & & 1500 \\
\hline 7439-92-1 & Lead & & $<0.38$ & & 19 \\
\hline 7440-65-5 & Yttrium & & $<0.02 \measuredangle 1$ & & 2 \\
\hline
\end{tabular}




\begin{tabular}{|c|c|c|c|c|c|}
\hline 7429-90-5 & Aluminum & \multirow{6}{*}{ MV1829S } & $<1.5$ & \multirow{6}{*}{ W1829S } & 9.4 \\
\hline 7440-41-7 & Beryllium & & $<0.0038$ & & $<0.0021$ \\
\hline 7440-43-9 & Cadmium & & $<0.023$ & & $<0.023$ \\
\hline 7439-89-6 & Iron & & $<1.5$ & & {$[6.0]$} \\
\hline 7439-92-1 & Lead & & $<0.38$ & & $<0.38$ \\
\hline $7440-65-5$ & Yttrium & & $<0.023$ & & $<0.023$ \\
\hline $7429-90-5$ & Aluminum & \multirow{6}{*}{ MV1829T } & {$[4.5]$} & \multirow{6}{*}{ W1829T } & 450 \\
\hline 7440-41-7 & Beryllium & & $<0.0038$ & & 0.022 \\
\hline 7440-43-9 & Cadmium & & $<0.023$ & & $<0.023$ \\
\hline 7439-89-6 & Iron & & {$[4.0]$} & & 420 \\
\hline $7439-92-1$ & Lead & & $<0.38$ & & [1.0] \\
\hline $7440-65-5$ & Yttrium & & $<0.023$ & & 0.28 \\
\hline 7429-90-5 & Aluminum & \multirow{6}{*}{ MV1829U } & 7.5 & \multirow{6}{*}{ W1829U } & 1200 \\
\hline 7440-41-7 & Beryllium & & $<0.0038$ & & 0.1 \\
\hline 7440-43-9 & Cadmium & & $<0.023$ & & 0.24 \\
\hline 7439-89-6 & Iron & & 6.3 & & 1200 \\
\hline 7439-92-1 & Lead & & $<0.38$ & & 19 \\
\hline $7440-65-5$ & Yttrium & & $<0.023$ & & 1.6 \\
\hline 7429-90-5 & Aluminum & \multirow{6}{*}{ MV1829V } & 5.9 & \multirow{6}{*}{ W1829V } & 1700 \\
\hline 7440-41-7 & Beryllium & & $<0.0038$ & & 0.15 \\
\hline $7440-43-9$ & Cadmium & & $<0.023$ & & 0.93 \\
\hline 7439-89-6 & Iron & & {$[4.8]$} & & 1700 \\
\hline 7439-92-1 & Lead & & $<0.38$ & & 27 \\
\hline $7440-65-5$ & Yttrium & & $<0.023$ & & 2.1 \\
\hline
\end{tabular}

